
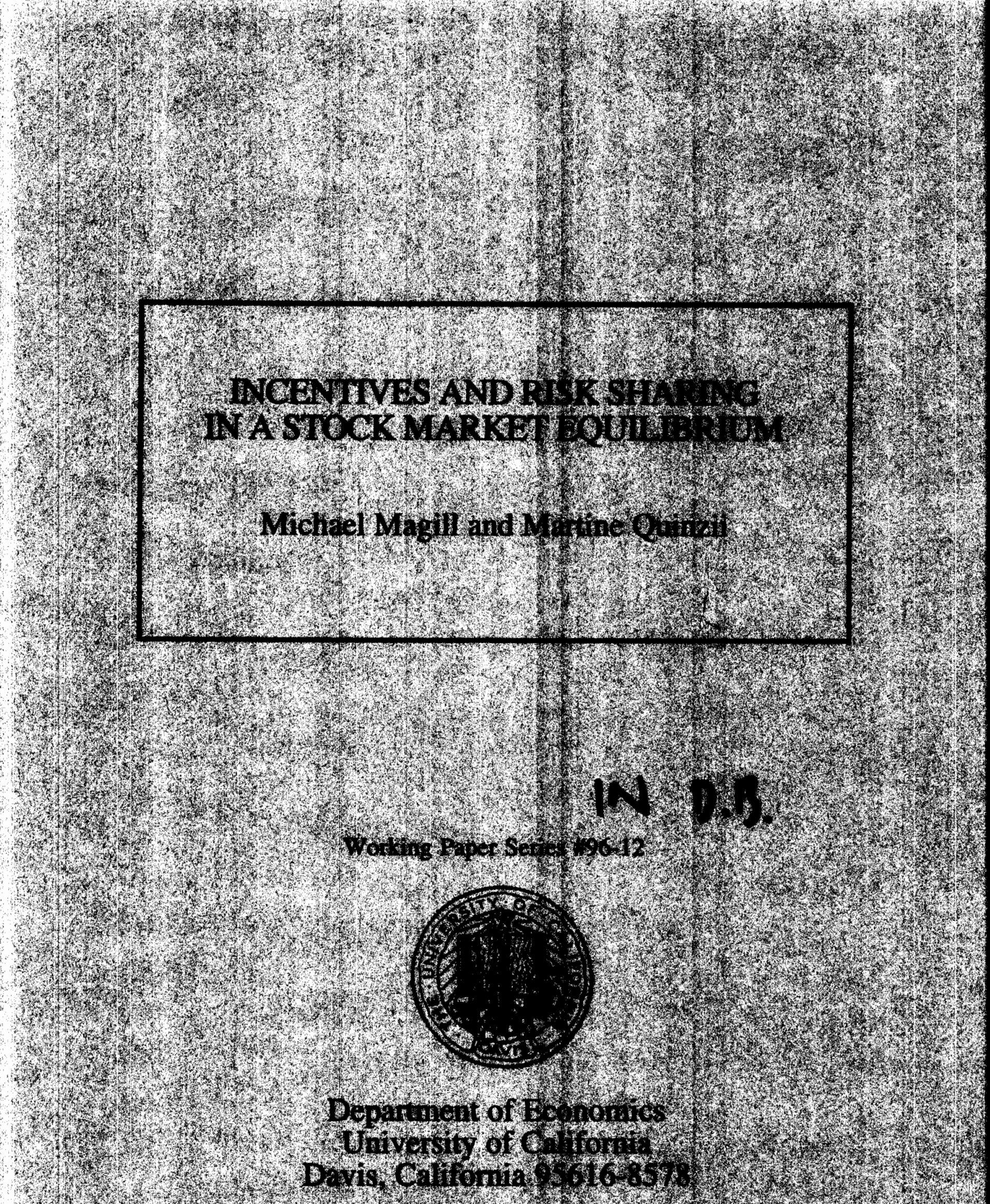


\title{
Incentives and Risk Sharing in a Stock Market Equilibrium
}

\author{
Michael Magill \\ University of Southern California
}

and

Martine Quinzii

University of California, Davis

\author{
Working Paper Series No. 96-12 \\ December, 1996
}

The first version of this paper was presented at the Conference in Honor of Herbert Scaft, September 29-30, 1995, Yale University. We are grateful to Kenneth Arrow, John Geanakoplos,

Peter Hammond, Jean-JacquesLaffont, Peter DeMarzo and Robert Townsend for helpful discussions and to participants at the SEDC Conference, ITAM, Mexico City and the SITE Summer Workshop, Stanford University, for interesting comments. The paper was revised in April 1996 and this version completed in October 1996.

Note: The Working Papers of rhe Department of Economics, University of California, Davis, are preliminary materials circulated to invite discussion and critical comment. These papers may be freely circulated but to protect their tentative character they are not to be quoted without the permission of the author. 
Introduction

\section{Incentives and Risk Sharing in a Stock Market Equilibrium}

\section{A. Introduction}

Economists have long been ambivalent on the merits of the stock market. On the one hand, the capital asset pricing model (CAPM), which is the basis for the modern theory of finance, emphasizes the merit of the stock market for diversifying the idiosyncraic risks and sharing the aggregate risks of productive activity. On the other hand, the traditional view of the classical economists, revived in modern times by Adolph Berle and Gardiner Means (1932), Michael Jensen and William Meckling (1976) and the ensuing agency-cost literature, emphasized the negative effect on incentives of the separation of ownership and control implied by the corporate form of ownership. This paper provides a framework for reconciling these two perspectives and shows the circumstances under which the stock market can provide an optimal trade-off between the beneficial effect of risk sharing and the distortive effect on incentives.

The risk-sharing role of the stock market can not be studied without a general equilibrium model. We adopt the simplest model which permits the simultaneous analysis of production, risk-sharing and financing decisions - namely the two-period general equilibrium model of Peter Diamond (1967). In the spirit of Frank Knight (1921) we model the firm as an entity arising from the organizational ability, foresight and initiative of an entrepreneur. The activity of a firm consists in combining entrepreneurial effort and physical input (the value of capital and non-managerial labor) at an initial date: this gives rise to a random profit stream at the next date. In addition to entrepreneurs there is another class of agents which we call investors: they have initial wealth at date 0 but no productive opportunities.

Consider the typical situation where entrepreneurs do not have sufficient initial wealth to pay for the capital investment required to operate their firms, and would furthermore like to find some way of sharing the risks involved in their productive activity. All the elements of mutually beneficial exchange are present, and it is the role of financial markets to make such exchange possible. Suppose however that the trades on the financial markets are made before entrepreneurs choose the level of effort to invest in their firms, and moreover, that this effort is not observable or verifiable by other agents. These are realistic assumptions, since arrangements for financing have to be made before production can take place, and in an uncertain world it is difficult to assess to what extent a high level of output is due to a high level of effort or to a 
Introduction

favorable exogenous shock. In these circumstances, exchange on the financial markets may lead to a moral hazard problem: an additional friction must however be present in order for this to occur. In the standard general equilibrium model uncertainty is described by an underlying state space which represents the exogenous shocks which can affect the output of the fims. If insurance contracts could be written contingent on the occurrence of these states of nature, then the problem of financing (investment and risk sharing) could be solved without distorting incentives, by leaving every entrepreneur the full owner of the output to which his effort gives rise (see Section I). This could only happen in the idealized and rather unlikely situation where the business risks to which entrepreneurs are exposed are essentially exogenous, and sufficiently simple so that they can be foreseen and described in advance and verified (by third parties) ex post. If business risks were indeed of this kind, we would never observe equity markets: they would not be needed for risk sharing and would only distort incentives.

To have a model consistent with what we observe - namely equity markets - the risks to which businessmen are typically exposed must be sfficiently complex and difficult to identify to make it unpractical to write insurance contracts contingent on their occurrence. Since the realized output of firms is readily observable, it is not surprising that the principal instruments for financing business activity and sharing its risks, namely debt, equity and bankruptcy are contracts contingent on the output of firms. In this paper we assume that debts are always repaid, leaving the analysis of bankruptcy for subsequent research. This permits us to study a model which lies close to the traditional risk-sharing model of finance, while at the same time incorporating the new effects introduced by moral hazard and incentives.

The concept of equilibrium that we propose for the stock market can be understood as taking to their logical conclusion, in a general equilibrium model, the ideas introduced by Jensen and Meckling (1976) in a partial equilibrium framework. They argued that the owner-manager of a firm has less incentive to make effort ${ }^{1}$ the smaller his ownership share - and that investors,

'The moral hazard problem studied by Jensen and Meckling, and most of the subsequent literature, is the consumption of perquisites out of the firm's available funds. We feel that the effort (initiative, resourcefulness, planning and follow through) invested by an entrepreneur in his firm is more fundamental in determining its output, and hence that of the economy as a whole, than the extent to which he draws perquisites out of the fim. Strangely, although their whole analysis is expressed in terms of perquisites, this was also their opinion. 'We shall continue to characterize the agency conflict between the owner-manager and outside shareholders as deriving from the manager's tendency to appropriate perquisites out of the firm's resources for his own consumption. However, we do not mean to leave the impression that this is the only or even the most important source of conflict. Indeed, it is likely that the most important conflict arises from the fact that as the manager's ownership claim falls, his incentive to devote significant effort to creative activities such as searching out new profitable ventures falls." (Jensen-Meckling, 1976, p. 313). 
Introduction

knowing this, will reduce the price they are prepared to pay for the firm. In turn, the ownermanager chooses the optimal amount of equity to sell, fully aware that the more equity he sells, the smaller the price the market will accept, to pay for his shares. In our general equilibrium model more variables enter than just the ownership share - each entrepreneur decides on the capital investment for his firm, how to finance it by a combination of debt and equity, and how to diversity his risks by buying shares in other fimms. All these investment-financing decisions influence the entrepreneur's choice of effort, and this in turn influences the payoffs that outside investors will obtain.

In the spirit of rational expectations, agents are assumed to correctly anticipate the outputs of the firms - this amounts to assuming that they can deduce the effort that entrepreneurs will invest in their firms. The new element in the concept of equilibrium is the formalization of the last (and crucial) feedback - namely, that when choosing their investment-financing variables, entrepreneurs take into account the fact that the market uses their observed trades on the financial markets to deduce what their associated effort will be. To formalize this idea we introduce the concept of price perceptions. To decide whether an investment-financing plan is optimal, an entrepreneur needs to evaluate what would happen if he were to change this plan. His price perceptions describe how he perceives that the price of his equity would change, were he to change his investment-financing plan. We assume that these price perceptions are rational (i.e. entrepreneurs think that investors will correctly deduce from their investment-financing decision what their effort and the associated output of their firm will be) and competitive (when an entrepreneur sells the same "product" as other firms - in our model this means the risk profile of the profit stream, which is the same for all firms operating in the same sector - then they think that the price of this "product" does not depend on their individual supply). Putting these ideas together leads to the concept of equilibrium (introduced in Section II) which we call a stock market equilibrium with rational, competitive price perceptions (an RCPP-equilibrium).

An important advantage of a general equilibrium model is that it permits the normative properties of markets to be studied. How well does the stock market perform in balancing incentives, risk sharing and inducements to invest? To answer this question we need an appropriate criterion of efficiency: the concept we use in Section III is the natural extension of the concept of constrained efficiency introduced by Diamond (1967); it respects both the limited available set of financial securities and the incentive constraints imposed by the nonobservability of effort. In Section III we show the rather surprising result that an RCPP-equilibrium is constrained efficient: the price perceptions provide precisely the nonlinear prices (incentive schemes) that 
Introduction

induce entrepreneurs and investors to efficiently allocate effort, investment and risk sharing.

An additional advantage of the concept of a stock market equilibrium that we introduce, is that it makes it possible to integrate two branches of the literature: the classical literature on portfolio choice and security pricing (the standard general equilibrium model of finance) and the literature on agency costs and their relation to capital structure, which following JensenMeckling (1976), have been studied in partial equilibrium models. Having a model with incentives which contains the classical risk-sharing model as a special case, permits one to study how the predictions of the standard model are modified by the presence of incentive effects. In Section IV we give examples of RCPP-equilibria and compare their predictions of portfolios and security prices with those of the standard finance model: we find that in an RCPP-equilibrium diversification is less extensive for entrepreneurs, since incentive considerations induce them to retain a larger share of their own firm and a smaller share of the equity of other firms than would be required solely on the basis of risk diversification: furthermore, incentives induce entrepreneurs to make much more extensive use of debt than would be predicted by the standard model. These differences translate into higher interest rates and lower risk prernia on the risky securities.

\section{B. Related Literature}

The study of the way ownership structure in business enterprise affects incentives has a long tradition in economics. The classical economists were uncompromisingly in favor of sole proprietorship, arguing that shared ownership has a negative effect on incentives (Adam Smith ${ }^{2}$ (1776), John Stuart Mill ${ }^{3}$ (1848), Alfred Marshall ${ }^{4}$ (1890)). The idea that share systems can be explained as a compromise between risk sharing and incentives was introduced in the sharecrop ping literature by Steven Cheung (1969) and Joseph Stiglitz (1974): for a more recent discussion of shared ownership (and the stock market) versus sole proprietorship see Peter Hammond (1993). The paper by Stiglitz was an early contribution to the literature on the principal-agent problem which subsequently gave rise to an extensive literature (see for example David Sappington (1991) for a survey). Although our paper is not set up as a principal-agent problem,

\footnotetext{
${ }^{2}$ See Book III, Chapter II of the Wealth of Nations for a criticism of the metayer system, the share system used in Continental Europe, by which the farmer and the landowner each obtained one half (metarius) of the output of the farm. See Book V, Part III for a vehement criticism of joint stock companies.

${ }^{3}$ See Book II, Chapters VI-VIII of Principles of Political Economy for a more balanced assessment of the metayer system and Book I, Chapter IX for a discussion of joint stock companies.

${ }^{4}$ See Book VI, Chapter X and Book IV, Chapter XII of Principles of Economics.
} 
Introduction

as we explain in Section III, the problem of constrained Pareto optimality can be viewed as a type of principal-agent problem, with the planner acting as a "benevolent" principal.

The idea that financial decisions of agents transmit information about characteristics or actions of agents that are not directly observable or knowable by the market, has been extensively explored in the finance literature. Concepts of equilibrium based on this idea and the idea of rational expectations have been used in many partial equilibrium models: for adverse selection in the signaling models of Stephen Ross (1977), and Hayne Leland and David Pyle (1977), and the subsequent literature (see Milton Harris and Artur Raviv (1992) for a survey); for problems of moral hazard by Michael Jensen and William Meckling (1976), Sanford Grossman and Oliver Hart (1982), and James Brander and Barbara Spencer (1989). This paper differs from these latter contributions in that it makes explicit in a general equilibrium setting with moral hazard how the market can resolve (or at least mitigate) the incentive problems created by asymmetry of information; it also provides a framework in which the risk-sharing function of financial markets and their disciplining role in attenuating the agency costs of firms can be studied simultaneously. This permits the agency costs and benefits of equity and debt to be balanced against the risk-sharing benefits and costs of these securities.

A simpler concept of rational expectations is present in all the literature on general equilibrium with incomplete markets (GEI) which began with the papers of Kenneth Arrow (1953) and Peter Diamond (1967), and subsequently evolved into an important branch of equilibrium analysis (for a survey of results in this area see Michael Magill and Wayne Shafer (1991)). We have chosen the simplest version of the GEI model with production, namely Diamond's model, to study how the agency theory of the firm could be incorporated into a general equilibrium analysis. It is well-known that a stock market equilibrium in Diamond's model is constrained efficient but that such a result can not in general be expected to hold in more complex GEI models. Since the problem of constrained inefficiency arising in an incomplete markets model with many goods or many periods is not directly related to the problems posed by incentives, we have chosen to take as a benchmark the simplest model in which financial markets lead to constrained efficiency in the absence of incentive effects.

An alternative approach to incorporating asymmetric information into general equilibrium, which is tantamount to extending Arrow-Debreu theory directly to a world with moral hazard and adverse selection has been proposed by Edward Prescott and Robert Townsend (1984a, 1984b). The contracts they consider are lotteries on an abstract consumption space. For the moment it is not clear to us how the two approaches are related: the contracts they study seem 


\section{Complete Insurance Markets and Sole Proprietorship}

very different from the standard debt and equity contracts which are the focus of our analysis.

The paper is organized as follows. Section I presents the basic model and considers the idealized (reference) case of complete insurance markets and sole proprietorship, where there is no conflict between risk sharing and incentives. Section II, which studies the more realistic setting where risk sharing involves a distortion of incentives, introduces the concept of an RCPP equilibrium. Section IV examines its normative properties and Section V presents examples of RCPP equilibria, contrasting them with the equilibria of a standard finance model.

\section{Complete Insurance Markets and Sole Proprietorship}

We begin by outlining the basic model of a two-period $(t=0,1)$ production economy, in which there are two types of agents, entrepreneurs and investors. An entrepreneur is an agent who contributes the effort (and initiative) required to undertake a productive activity: entrepreneurial effort, when combined with an investment of physical capital at date 0 leads to output at date 1. Two important features of the economy are that the effort that an entrepreneur invests in his firm is not observable by other agents, and that the date 1 output is uncertain. This creates two requirements for the efficient functioning of the economy: some way must be found to provide entrepreneurs with appropriate incentives to invest effort in their firms, and the productive risks of the economy must somehow be shared among the agents. In general, there is a conflict between these two requirements. In this section however, we study the ideal (reference) case where the ownership structure of firms (sole proprietorship) provides appropriate incentives for entrepreneurs, while financial markets permit risks to be shared optimally without distorting incentives.

\section{A. The Model}

Consider a two-period one-good model of an economy in which an investment of capital and effort at date 0 gives rise to an uncertain income stream at date 1 , the uncertainty being modelled by states of nature $(s=1, \ldots, S)$. There are $\mathrm{I}$ agents: each agent $\mathrm{i}$ has an initial wealth $w_{0}^{i}$ at date 0 , and if the agent is an entrepreneur, by investing capital (an amount of the good (income)) and effort $e^{i}$ at date 0 , he can obtain the uncertain stream of income at date 1 given by

$$
\mathbf{F}\left(\mathrm{z}_{7}^{\mathrm{i}} e^{i}\right)=\left(F_{1}^{i}\left(z^{i}, e^{i}\right), \ldots, F_{S}^{i}\left(z^{i}, e^{\prime}\right)\right)
$$

where $F^{\mathfrak{u}}(\cdot)$ is an increasing function of $\left(z^{i}, \mathrm{e}^{\mathrm{i}}\right)$ defined on $\mathrm{R}_{+}^{2}$. When agent $\mathrm{i}$ is an investor, we 


\section{Complete Insurance Markets and Sole Proprietorship}

set $\boldsymbol{F}^{\boldsymbol{i}} \equiv 0$. Each agent has a utility function $U^{\boldsymbol{i}}$, where $U^{i}\left(\boldsymbol{x}^{i}, \mathrm{e}^{\mathrm{i}}\right)$ is the utility associated with the consumption stream $\mathrm{x}^{\prime}=\left(x_{0}^{i}, x_{1}^{i}, \ldots, x_{S}^{i}\right)$ and the effortlevel $\mathrm{e}^{\prime} . U^{i}$, which is defined on the domain $\mathbf{R}_{+}^{S+1} \mathbf{x} \mathbf{R}_{+}$, is increasing in $\mathbf{x}^{\prime}$ and decreasing in e'. Since the effort $\mathrm{e}^{\prime}$ of an investor is not productive, it will always be set equal to zero. Each agent is thus characterized by $\left(U^{i}, w_{0}^{i}, \mathrm{~F}^{\prime}\right)$. Let $\mathcal{E}\left(U, w_{0}, F\right)$ denote the resulting economy with characteristics $U=\left(\mathrm{U}^{\prime}, \ldots, U^{I}\right), w_{0}=$ $\left(w_{0}^{1}, \ldots, w_{0}^{I}\right), \mathbf{F}=\left(\boldsymbol{F}^{1}, \ldots, \boldsymbol{F}^{I}\right)$.

\section{B. Incentives and Risk Sharing}

The output of a firm is the result of a joint investment of effort (by an entrepreneur) and physical capital, where the latter may be provided by the entrepreneur or by outside investors. How should the output of the firm be shared by the entrepreneur and the outside investors? From the point of view of incentives it has long been understood that any sharing of output between the provider of effort - here the entrepreneur - and the providers of capital, will distort the incentives of the entrepreneur, since he bears $100 \%$ of the marginal cost of his effort, and if he shares output with other agents, will receive less than $100 \%$ of the marginal benefit of his effort (see footnotes 2-4 above). Thus from the point of view of incentives, sole proprietorship is the sole form of ownership structure which does not distort incentives.

On the other hand, since sole proprietorship of firms leaves entrepreneurs fully exposed to the risks of their line of business, it must be complemented by some form of insurance markets on which the production risks of the economy can be shared. If the outcome is to be efficient, such insurance markets must not themselves be a new source of distortion of agents' incentives. For example, a contract providing insurance against low output for a firm, would certainly decrease the incentives of the entrepreneur to exert effort: thus the insurance contracts must be contingent on events whose (probability of) occurrence is independent of the actions of the agents. In the framework of this model this essentially means that the contracts would need to be based on the states of nature (exogenous shocks) whose occurrence is determined by "nature" rather than the economic agents. In practical terms this means that the business risks to which the firms are exposed would need to be sufficiently simple so that they can be traced to ex-ante describable and ex-post verifiable causes (states) which are independent of agents' actions, so that enforceable contracts can be written conditional on their occurrence. As the next proposition shows, if the business risks to which entrepreneurs are exposed are of this kind, then sole proprietorship combined with a system of insurance markets leads to an efficient outcome. 


\section{Complete Insurance Markets and Sole Proprietorship}

\section{Complete Insurance Markets for Business Risks}

If the states of nature are easy to describe and verify, and if contracts are costless to introduce and enforce, then we may without loss of generality assume that the market structure consists of a complete set of insurance contracts: an insurance contract ${ }^{5}$ for state $s$ pays one unit of income at date 1 if state s occurs and nothing otherwise and its price $\pi_{s}$ is payable at date 0 . $\mathbf{F}$ the ownership structure of frms consists of sole proprietorship, then entrepreneur $i$ will decide on the amount of capital z' to invest in his fim, on the effort $e^{i}$ to exert and on the portfolio of securities $\xi^{\boldsymbol{k}}=\left(\xi_{1}^{i}, \ldots, \xi_{S}\right)$ needed to finance the firm and smooth his consumption stream $\boldsymbol{x}^{i}=\left(x_{0}^{i}, x_{1}^{i}, \ldots, x_{S}^{i}\right)$, so as to maximize his utility $U^{i}\left(x^{i}, \mathrm{e}^{\mathrm{i}}\right)$. More precisely, if $\pi=\left(\pi_{1}, \ldots, \pi_{S}\right)$ is the vector of security prices, then the agent' $\mathrm{s}$ opportunity set is given by

$$
B\left(\boldsymbol{\pi} ; w_{0}^{i}, \boldsymbol{F}^{i}\right)=\left\{\begin{array}{l|l}
\left(\boldsymbol{x}^{i}, e^{i}\right) \in \mathbf{R}_{+}^{S+2} & \begin{array}{l}
x_{0}^{2} \leq w_{0}^{2}-\pi \boldsymbol{\xi}-z^{i} \\
x_{s}^{i} \leq \xi_{s}^{i}+F_{s}^{i}\left(z^{i}, e^{i}\right), s=1, \ldots, S \\
\left(z^{i}, \xi^{i}\right) \in \mathbf{R}_{+} \times \mathbf{R}^{S}
\end{array}
\end{array}\right\}
$$

We say that $\left(\mathrm{z}^{\prime}, \boldsymbol{\xi}^{i}\right)$ finances $\left(\mathrm{x}^{\mathrm{i}}, \mathrm{e}^{\mathrm{i}}\right)$ if together they satisfy the equations defining $B\left(\boldsymbol{\pi} ; w_{0}^{i}, \boldsymbol{F}^{i}\right)$, and we write $\left(\mathrm{x}^{\mathrm{i}}, \mathrm{e}^{\prime} ; \boldsymbol{z}^{i}, \boldsymbol{\xi}^{\mathbf{i}}\right) \in B\left(\boldsymbol{\pi}, w_{0}^{i}, \mathbf{F}^{\prime}\right)$.

A sole-proprietorship equilibrium with complete insurance markets for the economy $\mathcal{E}\left(U, w_{0}, \mathbf{F}\right)$ is a pair

$$
\left(\left(\overline{\boldsymbol{x}}^{i}, \bar{e}^{i}, \bar{z}^{i}, \overline{\boldsymbol{\xi}}^{i}\right)_{i=1}^{l}, \bar{\pi}\right)
$$

consisting of actions by the agents and prices for the securities such that

$$
\begin{aligned}
& \text { (i) }\left(\bar{x}^{i}, \bar{e}^{i} ; \bar{z}^{i}, \bar{\xi}^{i}\right) \in \operatorname{argmax}\left\{u^{i}\left(x^{i}, e^{i}\right) \mid\left(\mathrm{x}, \mathrm{e}^{\mathrm{i}}\right) \in B\left(\overline{\boldsymbol{\pi}}, w_{0}^{i}, F^{i}\right)\right\}, \quad i=1, \ldots, I \\
& \text { (ii) } \sum_{i=1}^{I} \bar{\xi}_{s}^{i}=0, \quad s=1, \ldots, S
\end{aligned}
$$

(i) simply means that $\left(\mathrm{x}^{\mathrm{i}}{ }^{2} \vec{e}^{i}\right)$ is an optimal consumption-effort decision of agent $i$, and that this is financed by the investment-portfolio decision $\left(\bar{z}^{i}, \overline{\boldsymbol{\xi}}^{i}\right)$. (ii) requires that every buyer of an Arrow security $s$ is matched to a seller, for $s=1, \ldots, \mathrm{S}$. Note that these equations imply that

\footnotetext{
salso called an Arrow security.
} 


\section{Complete Insurance Markets and Sole Proprietorship}

the feasibility conditions

$$
\begin{aligned}
& \sum_{i=1}^{I} \bar{x}_{0}^{i} \leq \sum_{i=1}^{I} w_{0}^{i}-\sum_{i=1}^{I} \bar{z}^{i} \\
& \sum_{i=1}^{I} \bar{x}_{s}^{i} \leq \sum_{i=1}^{I} F_{s}^{i}\left(\bar{z}^{i}, \bar{e}^{i}\right), \quad s=1, \ldots, S
\end{aligned}
$$

are satisfied at the equilibrium.

Proposition 1: A sole-proprietorship equilibrium with complete insurance markets for the economy $\mathcal{E}\left(\boldsymbol{U}, \boldsymbol{w}_{\mathbf{0}}, F\right)$ is Pareto optimal.

Proof: Suppose the equilibrium $\left(\left(\bar{x}^{i}, \bar{e}^{i}, \bar{z}^{i}, \bar{\xi}^{i}\right)_{i=1}^{I}, \bar{\pi}\right)$ is not Pareto optimal. Then there is a feasible allocation $(\mathrm{x}, \hat{e})$ such that $u^{i}\left(\hat{\boldsymbol{x}}^{i}, \hat{e}^{i}\right) \geq u^{i}\left(\overline{\boldsymbol{x}}^{i}, \bar{e}^{i}\right), i=1 \ldots, I$ with strict inequality for at least one $i$. The feasibility of $(\hat{\boldsymbol{x}}, \hat{\boldsymbol{e}})$ implies that there exist capital and effort allocations $\left(\hat{z}^{i}, \hat{e}^{i}\right)_{i=1}^{I}$ such that (1) and (2) are satisfied with $\left(\bar{z}^{i}, \vec{e}^{i}\right)$ replaced by $\left(\hat{z}^{i}, \mathrm{~d}^{\mathrm{i}}\right)$. For each agent $\mathrm{i}$, the portfolio of Arrow securities $\hat{\boldsymbol{\xi}}^{\mathrm{i}}=\hat{\boldsymbol{x}}_{1}^{\mathrm{i}}-F^{i}\left(\widehat{z}^{i}, \widehat{e}^{i}\right)$, where $\hat{x}_{1}^{i}=\left(\hat{x}_{1}^{i}, \ldots, \hat{x}_{S}^{i}\right)$, ensures that $\left(\hat{\boldsymbol{x}}^{i}, \hat{e}^{i}, \hat{z}^{i}, \hat{\boldsymbol{\xi}}^{i}\right)$ satisfies the date 1 budget equations. Since this action was not chosen by the agent under the price vector $\bar{\pi}$, it cannot be affordable at date 0 . Thus

$$
\hat{x}_{0}^{i} \geq w_{0}^{i}-\bar{\pi} \hat{\xi}^{i}-\hat{z}^{i}, \quad i=1, \ldots, I
$$

with strict inequality for an agent who strictly prefers $\left(\hat{\boldsymbol{x}}^{i}, \hat{e}^{i}\right)$. Since there is at least one such agent

$$
\sum_{i=1}^{I} \hat{x}_{0}^{i}>\sum_{i=1}^{I} w_{0}^{i}-\bar{\pi} \sum_{i=1}^{I} \hat{\xi}^{i}-\sum_{i=1}^{I} \hat{z}^{i} \geq \sum_{i=1}^{I} w_{0}^{i}-\sum_{i=1}^{I} \hat{z}^{i}
$$

since $\sum_{i=1}^{I} \widehat{\boldsymbol{\xi}}^{i} \leq 0$ and, by monotonicity of agents' preferences, $\bar{\pi}_{\boldsymbol{s}}>0$ for every state. This contradicts the feasibility of $(\widehat{x}, \hat{e})$ at date 0 , completing the proof.

\section{Interpretation of Proposition 1}

The interesting feature of this proposition is that it requires that the ownership structure of f i $\mathrm{rm}$ consist of sole proprietorship when incentive effects are present. It shows that the standard formulation of the First Theorem of Welfare Economics in an Arrow-Debreu production economy in which there is shared ownership of firms is rather misleading. The usual argument is that shared ownership does not present a problem since, with complete markets, all shareholders agree that the firm should maximize the present value of its profit; to be correct this 


\section{The Stock Market and Moral Hazard}

reasoning requires that the realized profit of a firm does not depend in any way on managerial effort, initiative and resourcefulness - in short, the entire managerial element in the running of a firmmust be factored out. Clearly the result is not at all robust: for once it is recognized that firms are run by entrepreneurs (managers) who need to be rewarded to perform efficiently, and that typically there is a small subset of high level managers - in our idealized case a single entrepreneur - who is ultimately "in charge" and accounts for the successful operation of a firm, then shared ownership no longer leads to Pareto optimality. For if there is shared ownership then the choice of effort by an entrepreneur is determined by the first-order condition

$$
\frac{\partial u^{i}\left(x^{i}, e^{\prime}\right) / \partial e^{i}}{\partial u^{i}\left(x^{i}, e^{i}\right) / \partial x_{0}^{i}}=\theta_{i}^{i} \sum_{s=1}^{c} \bar{\pi}_{s} \frac{\partial F_{s}^{i}\left(z^{i}, e^{i}\right)}{\partial e^{i}}
$$

where $\theta_{i}^{*}$ is the entrepreneur's ownership share of the firm. Proposition 1 implies that the firstorder condition for Pareto optimality is the same as the first-order condition for an equilibrium with sole proprietorship: but this implies that $\theta_{i}^{i}$ must equal one. Thus if there are complete insurance markets and if decision making in each firm is concentrated in the hands of a single entrepreneur, then sole proprietorship is necessary as well as sufficient for Pareto optimality. The insurance markets take care of risk sharing and sole proprietorship provides the right incentives: in such an economy shared ownership has no role to play and would only serve to distort the entrepreneurs' incentives.

\section{The Stock Market and Moral Hazard}

The previous section has identified an ideal ownership and financing structure for solving society's problem of providing incentives and sharing risks for the entrepreneurial economy under consideration. While it is clear that sole proprietorship provides excellent incentives for entrepreneurs, it is much less clear that the insurance markets which are needed to complement this type of ownership structure can be made to function. In practice the events which determine the success or failure of businesses are not only influenced by the actions of entrepreneurs, but are so numerous and of such complexity that they make the writing and enforcement of contingent contracts to all intents and purposes, unpractical.

Given the unfeasibility of such insurance markets, perhaps the most important way of coping with society's production risks in a modern economy is through the shared ownership of firms achieved by trading equity contracts on a stock market. However as we saw in the previous section, shared ownership inevitably affects the incentives of entrepreneurs. The object of this 


\section{The Stock Market and Moral Hazard}

section is to introduce a concept of equilibrium which explicitly takes into account the incentive effects of trading ownership shares of firms on a market.

\section{A. Assumptions}

We begin by introducing some additional assumptions on the characteristics of the economy $\mathcal{E}\left(\boldsymbol{U}, \boldsymbol{w}_{0}, \mathbf{F}\right)$. Agents' utility functions are taken to be separable

$$
U^{i}\left(x^{i}, \mathrm{e}^{\prime}\right)=u_{0}^{i}\left(x_{0}^{i}\right)+\mathrm{uf}\left(x_{1}^{i}, \ldots, x_{S}^{i}\right)-\mathrm{c}^{\prime}\left(\mathrm{e}^{\mathrm{i}}\right)
$$

where the functions $u_{0}^{i}, u_{1}^{i}$ are strictly concave increasing, and $c^{\prime}$ is convex increasing. These functions are differentiable on their domains, and satisfy the boundary conditions 6

$$
u_{0}^{i \prime}\left(x_{0}^{i}\right) \longrightarrow \infty \text { if } x_{0}^{i} \longrightarrow 0, \quad\left\|\nabla u_{1}^{i}\left(x_{1}^{i}\right)\right\|-\infty \text { if } x_{1}^{i} \longrightarrow \partial R_{+}^{S}, \quad \text { and } c^{i \prime}(0)=0
$$

In short, consumption is essential in all states and effort is essentially costless for small levels of effort.

On the production side, we assume that the economy is composed of $\boldsymbol{A}$ sectors (production activities) $a=1, \ldots, A$ with $\boldsymbol{A}<\mathbf{I}$. All entrepreneurs operating in the same sector $a$ are exposed to the same risks, the risks in sector a being characterized by the positive income stream $\eta^{\alpha}=\left(\eta_{1}^{\alpha}, \ldots, \eta_{S}^{\alpha}\right)$. Each entrepreneur $\mathrm{i}$ is assumed to have the ability and experience required to operate in one sector $\mathbf{a}=\alpha(i)$, and the entrepreneur's date 1 profit function has the multiplicative form

$$
\boldsymbol{F}^{i}\left(z^{i}, e^{i}\right)=f^{i}\left(z^{i}, e^{i}\right) \eta^{\alpha(i)}
$$

the function $f^{i}$ expressing the specific ability of agent $\mathrm{i}$ for transforming an initial investment of capital and effort $\left(z^{i}, \mathrm{e}^{\prime}\right)$ into a profit streain at date 1 . To permit the same notation to be used for both investors and entrepreneurs we introduce a dummy sector, called sector $\mathrm{A}+1$, whose income stream is zero i.e. $\eta^{\alpha}=0$ if $a=\mathrm{A}+1$. When $\mathrm{i}$ is an investor $\left(F^{\mathfrak{\imath}} \equiv 0\right)$, then by convention $\alpha(i)=\mathrm{A}+1 . \mathrm{f}^{\prime}\left(\mathrm{z}^{\mathrm{i}}, \mathrm{e}^{\mathrm{i}}\right)$ is assumed to be a differentiable, increasing function of $\left(\mathrm{t}^{\mathrm{i}}, \mathrm{e}^{\prime}\right)$ which satisfies $f^{i}\left(0, \mathrm{e}^{\prime}\right)=f^{i}\left(z^{i}, 0\right)=0$ (both inputs are essential). While $f^{i}$ is concave in $z^{i}$ reflecting decreasing returns to capital, concavity in $\mathrm{e}^{\prime}$ is not needed as long as the marginal cost of effort increases faster than its marginal product (see Assumption MCMP(a) below).

\footnotetext{
${ }^{6} \nabla u_{1}^{i}=\left(\frac{\partial u_{i}^{i}}{\partial x_{1}^{i}}, \ldots, \frac{\partial u_{i}^{i}}{\partial-i}\right)$ denotes the gradient of $u_{1}^{i}$ and $\partial R_{+}^{s}$ is the boundary of the non-negative orthant of $\mathrm{R}^{\mathrm{S}}$
} 


\section{The Stock Market and Moral Hazard}

The multiplicative factor structure ${ }^{7}$ in (3) was first introduced by Diamond (1967). Its principal advantage is that it leads to a competitive pricing of sectoral risks which is well-defined even if the financial markets are incomplete. By altering his actions $\left(z^{i}, \mathrm{e}^{\prime}\right)$, entrepreneur $i$ can influence the expected value of the profit stream of his firm, but if there are many other firms operating in the same sector, whose shares are traded on the stock market, then he cannot influence the "risk price" of the profit stream that he sells i.e. the price that investors are willing to pay for the basic income stream (factor) $\eta^{\alpha(i)}$ of his sector. More general risk structures for the production functions $F^{*}$ introduce difficulties for a competitive pricing of risks in a model with incomplete markets, which we want to avoid in this paper in order to concentrate on the new element introduced by incentives.

In this section we accept as a fact that the complexity of business risks, when combined with the unobservability of entrepreneurial effort, makes the writing and enforcement of contracts contingent on states unfeasible. We assume that the opportunities for sharing the production risks in the economy are those that can be obtained through shared ownership of the firms. There is thus a stock market on which entrepreneurs, who have the initial property rights to the profit streams of their firms (since this is the result of their effort and initiative) can sell a part of their ownership shares to obtain funds for capital investment, and can buy shares in other firms in order to diversify their risks. We assume that after selling ownership shares of their firms, entrepreneurs remain the sole managers of their firms even though they hold less than $100 \%$ of the shares: they are thus "owner-managers" in the sense of Jensen-Meckling (1976). In addition to obtaining funds by issuing equity, we assume that firms can also issue debt. To simplify the analysis we assume that the penalty for bankruptcy is infinite: there is thus a single instrument traded on the bond market, which is the "default-free" bond.

\section{B. Budget Sets}

To make clear how the timing of agents' decisions takes place we divide date 0 into two subperiods $0_{1}, 0_{2}$. In subperiod $0_{1}$ entrepreneurs use the financial markets to obtain the capital required to set up their firms and to diversity their risks: in the second subperiod $0_{2}$, after the investment and financing decisions have been made, firms become "operative" and entrepreneurs decide on the appropriate effort to invest in the running of their firms. At date 1 "nature" chooses a state of the world (shock): production takes place and profit is realized.

\footnotetext{
${ }^{7}$ This is in essence a nonlinear version of activity analysis, the vector $\mathbf{q}^{\mathbf{a}}$ constituting the "activity" (income stream) of sector a (see Tjalling Koopmans (1951)).
} 
In subperiod $0_{1}$ entrepreneur $i$ decides on the amount of capital $z^{i}$ to invest in his firm, on the amount to borrow $b^{i}$ (if $b^{i}>0$, lend if $b^{i}<0$ ), on the share $\left(1-\theta_{i}^{i}\right.$ ) of his firm to sell and on the shares $\theta_{k}^{\boldsymbol{i}}$ of other fims $\mathrm{k} \neq \mathrm{i}$ to buy: let $8^{\prime}=\left(\mathrm{Of}, \ldots, \theta_{I}^{\boldsymbol{i}}\right)$ denote the agent's portfolio of equity contracts. Let $q_{0}$ denote the price of the bond and let $\mathrm{Q}=\left(Q_{1}, \ldots, Q_{I}\right)$ denote the vector of prices of the firms' shares: thus $Q_{i}$ is the price of full ownership of firm $i$, and if agent $i$ is not an entrepreneur i.e. if $\mathrm{F}\left(\mathrm{z}^{\mathrm{i}}, \mathrm{e}^{\prime}\right) \equiv 0$, then $Q_{\boldsymbol{i}}=0$. The accountability of agent $\mathrm{i}$ requires that the following budget equations be satisfied

$$
\begin{aligned}
& x_{0}^{i}=w_{0}^{i}+q_{0} b^{i}-\sum_{k \neq i} \theta_{k}^{i} Q_{k}+\left(1-\theta_{i}^{i}\right) Q_{i}-z^{i} \\
& x_{s}^{i}=-b^{i}+\sum_{k \neq i} \theta_{k}^{i} f^{k}\left(z^{k}, e^{k}\right) \eta_{s}^{\alpha(k)}+\theta_{i}^{i} f^{i}\left(z^{i}, e^{i}\right) \eta_{s}^{\alpha(i)}, \quad s=1, \ldots, S
\end{aligned}
$$

the consumption in each state being non-negative. If $\mathbf{s f}=\left(\mathrm{xi}, \ldots, x_{S}^{i}\right)$ denotes the date 1 consumption stream, and if $1=(1, \ldots, 1)$ denotes the riskless income stream at date 1 , then the $S$ equations in (5) can be written in the more condensed vector form

$$
x_{1}^{i}=-b^{i} 1+\sum_{k \neq i} \theta_{k}^{i} f^{k}\left(z^{k}, e^{k}\right) \eta^{\alpha(k)}+\theta_{i}^{i} f^{i}\left(z^{i}, e^{i}\right) \eta^{\alpha(i)}
$$

The agents' financial transactions $\left(\mathrm{z}^{\mathrm{i}}, \mathrm{b}^{\mathrm{i}}, \boldsymbol{\theta}^{\boldsymbol{i}}\right)_{i=1}^{I}$ carried out in subperiod $0_{1}$ are assumed to be mutually observable. Thus an investor who spends money buying shares of firm i, knows exactly how this money is used by entrepreneur $\mathrm{i}$ : how much is invested in the firm $\left(z^{i}\right)$, how much goes to private consumption $\left(x_{0}^{1}\right)$, etc ...; he also knows agent $i$ 's sources of income at date 1 , his debt payment $-b^{2}$, and the dividends he will receive from the different firms in the economy. What the investor cannot observe when buying his shares in firm $i$ is the effort entrepreneur $\mathbf{i}$ will invest in his firm: this decision will be made by the entrepreneur in subperiod $\mathrm{O}_{2}$, and the best the investor can do is to form an expectation about what e' will be.

\section{Qotimal Effort Function}

Consider how entrepreneur $\mathrm{i}$ chooses his optimal effort in subperiod $\mathbf{0}_{2}$. Given that this decision is made after the financing decision $\left(z^{i}, b^{\prime}, \theta^{i}\right)$ has been chosen, the entrepreneur will choose the effort level e' which maximizes $u_{1}^{i}\left(x_{1}^{i}\right)-c^{\prime}\left(e^{i}\right)$, the date 1 consumption stream $x_{1}^{i}$ being given by (6). If agent $i$ correctly anticipates the effort of other entrepreneurs $(\mathrm{k} \neq \mathrm{i})$, then he will correctly anticipate what his date 1 outside income stream $\mathbf{m}^{\mathbf{i}}$ will be, where

$$
\boldsymbol{m}^{i}=\boldsymbol{m}^{i}\left(b^{i},\left(\theta_{k}^{i}\right)_{k \neq i}\right)=-b^{i} 1+\sum_{k \neq i} \theta_{k}^{i} f^{k}\left(z^{k}, e^{k}\right) \eta^{\alpha(k)}
$$




\section{The Stock Market and Moral Hazard}

The agent's choice of effort is thus the solution of the problem

$$
\max _{e^{i} \geq 0}\left\{u_{1}^{i}\left(m^{i}+\theta_{i}^{i} f^{i}\left(z^{i}, e^{i}\right) \eta^{\alpha(i)}\right)-c^{i}\left(e^{i}\right)\right\}
$$

where the parameters $\left(m^{i}, z^{i}, \theta_{i}^{i}\right) \in \mathbf{R}^{\mathcal{S}} \times \mathbb{R}_{+}^{2}$ must be such that $\mathrm{m}^{\mathrm{i}}+\theta_{i}^{i} f^{i}\left(z^{i}, e^{i}\right) \eta^{\alpha(i)} \geq 0$ for some $e^{i} \geq 0$ : let $\mathcal{D}$ denote this domain.

To ensure that the problem $(\mathrm{E})$ has a solution and that each entrepreneur's technology is sufficiently productive relative to his cost of effort to make it worthwhile to put his firm into operation, we make the following assumption.

Assumption MCMP (marginal cost-marginal product).

(a) For all $\mathrm{r}^{\mathrm{i}}>0, c^{i \prime}(\cdot) / \frac{\partial f^{\prime}\left(z^{i} \cdot\right)}{\partial e^{i}}$ is increasing and tends to $\mathrm{m}$ when $\mathrm{e}^{\prime} \mathrm{m}$.

(b) There is a smooth path $e^{i}:[0,1] \quad \mathrm{R}_{+}^{2}$ with $e^{i}(0)=0$ and $e^{i \prime}(t)>0$ such that

$$
\lim _{t \rightarrow 0} \frac{\partial f^{i}}{\partial z^{i}}\left(\mathrm{t}, \mathrm{e}^{\mathrm{i}}(\mathrm{t})\right)=\infty, \quad \lim _{\mathrm{t} \rightarrow 0} c^{i \prime}\left(e^{i}(t)\right) e^{i \prime}(t)<\mathrm{m}
$$

An entrepreneur who invests more effort in his firm becomes more productive, but effort also becomes more costly. Part (a) of the above assumption ensures that the percentage increase in the marginal cost of effort exceeds the percentage increase in its marginal product i.e. that the elasticity condition

$$
\frac{c^{i \prime \prime}\left(e^{i}\right)}{c^{i \prime}\left(e^{i}\right)} e^{i}>\left(\frac{\partial^{2} f^{i}\left(z^{i}, e^{i}\right) / \partial^{2} e^{i}}{\partial f^{i}\left(z^{i}, e^{i}\right) / \partial e^{i}}\right) e^{i}
$$

is satisfied. Since the marginal cost of effort rises faster than its marginal product, the optimal choice problem (E) has a solution: the monotonicity assumption ensures that the solution is unique (see Proposition 2). Part (b) of the assumption ensures that both at an equilibrium (defined in part (D)) and at a constrained Pareto optimal allocation (defined in Section III) every entrepreneur invests a positive amount of capital and effort in his firm: (b) ensures that if the entrepreneur were to operate at $\left(z^{i}, \mathrm{e}^{\mathrm{i}}\right)=(0,0)$, there would be a way of slightly increasing capital $\left(z^{i}=\mathrm{t}\right)$ and effort $\left(\mathrm{e}^{\prime}=\mathrm{e}^{\mathrm{i}}(\mathrm{t})\right)$ so that the increase in marginal utility arising from the increase in output exceeds the small marginal increase in the cost of effort: given the nature of the surface defined by $f^{i}\left(z^{i}, \mathrm{e}^{\prime}\right)$, the path $\mathrm{e}^{\mathrm{i}}(\mathrm{t})$ must be chosen so as to make capital very productive (typically $e^{i \prime}(t) \longrightarrow \mathrm{m}$ as $\mathrm{t} \longrightarrow 0$ ) by exploiting the fact that the cost of effort remains very small for small levels of effort.

Example. If $f^{i}\left(z^{i}, \mathrm{e}^{\prime}\right)=\left(z^{i}\right)^{\beta}\left(e^{i}\right)^{\gamma}$ and $\mathrm{c}^{\mathrm{i}}\left(\mathrm{e}^{\prime}\right)=\left(e^{i}\right)^{\delta}$, then $\operatorname{MCMP}(\mathrm{a})$ is satisfied if $\delta>\gamma$ and 


\section{The Stock Market and Moral Hazard}

$\operatorname{MCMP}(\mathrm{b})$ is satisfied if $6>\frac{\gamma}{i-\beta}$. The higher the power 6 , the flatter is the cast curve at zero, and the more readily MCMP is satisfied.

Proposition 2: (i) If Assumption MCMP(a) is satisfied, then for each $\left(m^{i}, z^{\mathrm{i}}, \theta_{i}^{i}\right) \in \mathcal{D}$ the problem (E) has a unique solution

$$
\mathrm{e}_{i}\left(\mathrm{~m}^{\mathrm{i}}, z^{i}, \theta_{i}^{i}\right)=\underset{e^{i} \geq 0}{\arg \max }\left\{u_{1}^{i}\left(\mathrm{~m}^{\mathrm{i}}+\theta_{i}^{\imath} f^{i}\left(\mathrm{z}^{\mathrm{i}}, e^{i}\right) \eta^{\alpha(i)}\right)-c^{i}\left(e^{i}\right)\right\}
$$

and $\tilde{e}^{i}$ is differentiable whenever $\tilde{e}^{i}\left(m^{i}, \mathrm{z}^{\mathrm{i}}, \theta_{i}^{i}\right)>0$.

(ii) If Assumption $M C M P(b)$ holds, then for all $\mathrm{x}^{\mathrm{i}}=\left(x_{0}^{i}, x_{1}^{i}\right) \in \mathbb{R}_{+}^{S+1}$ with $x_{0}^{i}>0$, there exist $\left(z^{i}, e^{\prime}\right) \gg 0$ such that

$$
u_{0}^{i}\left(x_{0}^{i}-z^{i}\right)+u_{1}^{i}\left(x_{1}^{i}+f^{i}\left(z^{i}, e^{i}\right) \eta^{\alpha(i)}\right)-c^{i}\left(e^{i}\right)>u^{i}\left(x_{0}^{i}\right)+u^{i}\left(x_{1}^{i}\right)
$$

Proof (See Appendix).

(7) expresses the fact that the effort exerted by an entrepreneur depends on his ownership share $\theta_{\boldsymbol{i}}^{\boldsymbol{i}}$ of his own firm, on the amount of capital that he has invested in it, and in addition depends on the stream of outside income $\mathrm{m}^{\mathrm{i}}$ that he receives which is independent of his own effort. Note that since $m^{2}$ is a function of his borrowing and of his equity shares in other firms $\left(b^{i},\left(\theta_{k}^{i}\right)_{k \neq i}\right)$, the optimal effort of entrepren $\epsilon^{\prime} \mathbf{u} \mathrm{i}$ is well-defined once he has chosen his financial variables $\left(\mathrm{z}^{\mathrm{i}}, b^{i}, \theta^{\boldsymbol{t}}\right)$.

\section{Stock Market Equilibrium}

Consider an investor who is thinking of buying shares of entrepreneur i's firm and can observe his financial decisions $\left(z^{i}, b^{i}, \theta^{i}\right)$. It would be "irrational" for the investor not to use this information to deduce what the most likely effort of entrepreneur $i$ will be. To be able to deduce $\widetilde{e}^{i}\left(z^{i}, b^{i}, \theta^{i}\right)$, however, the investor would need to know in addition to the entrepreneur's financial decisions, his characteristics $\left(u_{1}^{i}, c^{i}, f^{i}, \eta^{\alpha(i)}\right)$. In the analysis that follows we make the strong assumption that the agents' characteristics are common knowledge. Thus the investor can deduce from the financial variables $\left(\mathrm{z}^{\prime}, b^{i}, \boldsymbol{\theta}^{\boldsymbol{i}}\right)$ the effort that entrepreneur $\mathrm{i}$ will choose: in short, we suppose that every investor knows the entrepreneur's effort function $\tilde{e}^{i}\left(z^{i}, b^{\prime}, 8^{\prime}\right)$. In practice agents will probably not have such a precise knowledge of other agents' characteristics - however they are likely to have a good idea of "what makes entrepreneurs tick ${ }^{\mathrm{n}}$. Experienced investors are not readily fooled: they know that an entrepreneur who retains only a small share 


\section{The Stock Market and Morai Hazard}

of his firm and has a lot of outside income typically does not exert much effort to make his firm productive.

I investors correctly anticipate, through the price they are prepared to pay for each firm i, the effect of the financial decisions of entrepreneur $i$ on the effort that he invests in his firm, then it seems reasonable to suppose that each enirepreneur will come to understand this. Hence our second assumption: entrepreneurs know that investors will use their financial decisions as "signals" of the effort that they will exert in their fims. The next step is to incorporate these two assumptions into a concept of equilibrium.

The description of an equilibrium consists of two parts. The first is the standard part which enumerates the actions of the $\mathbf{I}$ agents, the prices of the $\mathbf{I}+1$ securities and the mutual compatibility of their actions under these prices. The second part describes the entrepreneurs' perceptions of the way their financial decisions affect the price that the "market" will pay for the shares of their firms, and ensures that these perceptions are compatible with the equilibrium prices. Let

$$
\tilde{Q}_{i}: \mathbf{R}_{+} \times \mathbf{R} \times \mathbf{R}_{+}^{I}-\mathbf{R}_{+}, i=1, \ldots, \mathbf{I}
$$

denote the price perception of each entrepreneur $\mathrm{i}$ and let $\mathrm{Q}=\left(\widetilde{Q}_{1}, \ldots, \widetilde{Q}_{I}\right)$. Thus $\widetilde{Q}_{i}\left(z^{i}, \mathrm{~b}^{\mathrm{i}}, \boldsymbol{\theta}^{i}\right)$ denotes the price that entrepreneur $i$ expects to receive if he sells the share $1-\theta_{i}^{i}$ of his firm, when his other financial decisions are given by $\left(\mathrm{z}^{\mathrm{i}}, \mathrm{b}^{\prime},\left(\theta_{k}^{i}\right)_{k \neq i}\right)$.

Definition 1: A stock market equilibrium with price perceptions $\widetilde{Q}$ is a triple

$$
\left((\overline{\boldsymbol{x}}, \overline{\boldsymbol{e}}, \overline{\boldsymbol{z}}, \overline{\boldsymbol{b}}, \overline{\boldsymbol{\theta}}),\left(\bar{q}_{0}, \overline{\boldsymbol{Q}}\right) ; \overline{\boldsymbol{Q}}\right)
$$

consisting of actions, prices and price perceptions such that

(i) for each agent $\mathrm{i},\left(\mathrm{x}^{\prime}, \bar{e}^{i}\right)$ maximizes $U^{i}\left(x^{i}, \mathrm{e}^{\prime}\right)$ among consumption-effortstreams such that 8

$$
\begin{aligned}
& x_{0}^{i}=w_{0}^{i}+\bar{q}_{0} b^{i}-\sum_{k \neq i} \bar{Q}_{k} \theta_{k}^{i}+\widetilde{Q}_{i}\left(z^{i}, b^{i}, \theta^{i}\right)\left(1-\theta_{i}^{i}\right)-z^{i} \\
& x_{1}^{i}=-b^{i} 1+\sum_{k \neq i} \theta_{k}^{i} f^{k}\left(\bar{z}^{k}, \bar{e}^{k}\right) \eta^{\alpha(k)}+\theta_{i}^{i} f^{i}\left(z^{i}, e^{i}\right) \eta^{\alpha(i)}
\end{aligned}
$$

for some $\left(z^{i}, b^{i}, \theta^{i}\right) \in \mathbb{R}_{+} \times \mathbf{R} \times \mathbf{R}_{+}^{I}$

(ii) $\tilde{Q}_{i}=\widetilde{Q}_{i}\left(\bar{z}^{i}, \bar{b}^{i}, \bar{\theta}^{i}\right), \mathrm{i}=1, \ldots, I$

(iii) $\sum_{i=1}^{I} \bar{b}^{i}=0 \quad$ (iv) $\sum_{i=1}^{I} \bar{\theta}_{k}^{i}=1, \quad k=1, \ldots, I$

\footnotetext{
${ }^{8}$ Whenever $k$ is not an entrepreneur, since $F^{k}\left(z^{k}, e^{k}\right) \equiv 0$, the shares $\theta_{k}^{i}$ are fictitious: they are shares of the zero vector. In this case we set $\theta_{i}^{i}=1, \theta_{k}^{i}=0, i \# \mathrm{k}$, so that the market clearing condition (iv) can be written symmetrically for all agents.
} 


\section{The Stock Market and Moral Hazard}

Thus in an equilibrium with price perceptions $Q$, each entrepreneur takes the prices and production plans of the other entrepreneurs as given, and correctly anticipates the effort they invest in their firms; he chooses his own actions, anticipating that those which are observable (his financial decisions) will influence the price that outside investors are prepared to pay for their shares in his venture, in the way indicated by the function $\widetilde{Q}_{i}\left(z^{i}, \mathrm{~b}^{\mathrm{i}}, \boldsymbol{\theta}^{i}\right)$. By (ii), the price perceptions are consistent with the observed equilibrium prices $Q$, and by (iii) and (iv), the bond and equity markets clear.

Without more precise assumptions on the price perceptions $\widetilde{Q}_{i}\left(z^{i}, b^{i}, \theta^{i}\right)$, this concept of equilibrium only incorporates the first assumption that we discussed above - namely that investors have correct expectations -- but it does not yet explicitly incorporate the second namely that entrepreneurs are fully aware of this fact. For example, the equilibrium concept in Definition 1 would be compatible with myopic expectations of the form $\widetilde{Q}_{i}\left(z^{i}, b^{i}, \theta^{i}\right) \equiv \bar{Q}_{i}, \mathrm{i}=$ $1, \ldots$, I. At first glance this might seem like the natural candidate for a concept of "competitive" equilibrium. However this is not a legitimate use of the assumption of price-taking behaviour, since $Q_{i}$ is not a "per-unit" price, but rather is the price of the whole firm. Competition means that identical goods, supplied by competing firms, have the same per-unit price and this price is perceived to be independent of the supply of any particular firm. The "goods" which are being supplied here are profit streams of the form $\mathrm{f}^{\prime}\left(\mathrm{z}^{\mathrm{i}}, e^{i}\right) \eta^{\alpha(i)}$. The factor $\eta^{\alpha}$ is identical for all firms operating in the same sector $a$ : competition thus implies that entrepreneuri takes the price of the income stream $\eta^{\alpha}$ as grven and independent of the amount that he supplies to the market. The notion of competition does not however explain how an entrepreneur should perceive that the "market" will evaluate the personalized part $f^{i}\left(z^{i}, \mathrm{e}^{\prime}\right)$, namely the "amount" of $\boldsymbol{\eta}^{\alpha}$ that he will supply when $\mathrm{e}^{\mathrm{i}}$ is not observable. To answer this part, the concept of rational expectations is more appropriate than the concept of competition. We are thus led to the following concept of equilibrium.

Definition 2: A stock market equilibrium with rational, competitive price perceptions, (RCPP) is an equilibrium $\left((\bar{x}, \bar{e}, \overline{\boldsymbol{z}}, \bar{b}, \bar{\theta}),\left(\bar{q}_{0}, \bar{Q}_{;} ; \widetilde{Q}\right)\right.$ with price perceptions in which the perception functions satisfy the following condition: there exist prices $\left(\bar{q}_{1}, \ldots, \bar{q}_{A}\right)$ for the sectoral income streams such that for $\mathrm{i}=1, \ldots, \mathbf{I}$

$$
\begin{aligned}
& \widetilde{Q}_{i}\left(z^{i}, b^{i}, \theta^{i}\right)=\bar{q}_{\alpha(i)} f^{i}\left(z^{i}, \tilde{e}^{i}\left(m^{i}, z^{i}, \theta_{i}^{i}\right)\right) \\
& \text { where } \mathrm{m}^{\mathrm{i}}=-b^{i} 1+\sum_{k \neq i} \theta_{k}^{i} f^{k}\left(\bar{z}^{k}, \bar{e}^{k}\right) \eta^{\alpha(k)}
\end{aligned}
$$


Thus to check if his financial decision $\left(\bar{z}^{i}, \bar{b}^{i}, \mathbf{8}^{\prime}\right)$ at equilibrium is optimal, entrepreneur $i$ forms expectations about what the price $\widetilde{Q}_{i}$ would be if he were to make an alternative financial decision $\left(z^{\prime}, b^{i}, 8^{\prime}\right)$. To form these expectations he takes the price $\bar{q}_{\alpha(i)}$ of one unit of his sectoral income stream $\eta^{\alpha(i)}$ as given ${ }^{9}$, and calculates that the market price of his firm will be $t^{i} \vec{q}_{\alpha(i)}$, if the market anticipates his profit will be $t^{i} \eta^{\alpha(i)}$. To evaluate $m^{i}$ in (10) he takes as given the effort $\bar{e}^{k}$ that other entrepreneurs $(\mathrm{k} \neq \mathrm{i})$ make given their financial choices $\left(\bar{e}^{k}=\right.$ $\left.\tilde{e}^{k}\left(\mathrm{~m}^{\mathrm{k}}, \bar{b}^{k}, \bar{\theta}_{k}^{k}\right)\right)$. This is the competitive part of his calculation.

To evaluate what the market anticipates his "output" $\mathrm{t}^{\mathrm{i}}$ will be, he draws on his knowledge of investor rationality: he anticipates that the market will deduce from $\left(\mathrm{m}^{\mathrm{i}}, z^{i}, \theta_{i}^{\mathbf{z}}\right)$ what his optimal effort will be, and thus anticipates that $t^{i}$ will be equal to $f^{i}\left(z^{i}, \widetilde{e}^{i}\left(m^{i}, z^{i}, \theta_{i}^{i}\right)\right)$. This is the rational-expectations part of his calculation.

An RCPP equilibrium ${ }^{10}$ describes a situation where entreprereuriai effort is not observable, but where all participants on the market use all available information to deduce the likely values of the hidden (moral hazard) variables - and all agents know this: in short, there is common knowledge of rationality.

\footnotetext{
${ }^{9}$ Note that the "competitive" price $\bar{q}_{a}$ can be deduced from the observable market prices $\bar{Q}_{i}$, only if there is at least one entrepreneur who is active in sector a. For if $f^{i}\left(\bar{z}^{i}, \bar{e}^{i}\right)>0$ for some $i$ with $\alpha(i)=a$, then (ii) in Definition 1 and (9) imply that $\bar{q}_{\alpha}=\bar{Q}_{i} / f^{i}\left(\bar{z}^{i}, \bar{e}^{i}\right)$. However if $f^{i}\left(\bar{z}^{i}\right.$, E) $)=0$ for all $\mathbf{i}$ with $\alpha(i)=\mathbf{a}$, then (ii) and (9) imply $\vec{Q}_{i}=0$, so that $\vec{q}_{\alpha}$ is indeterminate. In this latter case, the concept of equilibrium does not guarantee that the price $\bar{q}_{\alpha}$ used by an entrepreneur in sector a to reach the decision $\left(\bar{z}^{i}, \bar{e}^{i}\right)=0$ is "reasonable", since it does not correspond to an objective market signal. Assumption MCMP(b) avoids the conceptual difficulties that arise in these cases.

${ }^{10}$ In this paper we do not enter into a proof of the existence of an RCPP equilibrium. We can however indicate the ideas that can be used to establish existence. From the technical point of view, the main difference between this concept and a standard concept of competitive equilibrium is that the budget sets are not convex: both the nonlinear price perceptions $\widetilde{Q}^{i}\left(z^{i}, b^{i}, \theta^{i}\right)$ and the multiplicative terms $\theta_{i}^{i} f^{i}\left(z^{i}, e^{\prime}\right)$ introduce nonconvexities in the budget sets described in (i) of Definition 1 . When the characteristics are such that, at given prices $\left(q_{0}, q_{1}, \ldots, q_{A}\right)$ for the factors, the optimal choice of each agent is unique, then an equilibrium exists: we found that this property of uniqueness is satisfied for all the examples of equilibria of the type considered in Section $N$ that we have computed. When at some prices an agent' s optimal choice can be multivalued, since the choice correspondence is not convex valued, discontinuities in aggregate excess demand may arise which can prevent existence of an equilibrium. In this case, using the convexifying effect of large numbers, or more precisely the Shapley-Folkman theorem, we can prove that an approximate equilibrium exists, in which markets clear, up to a per-capita error, which can be made as small as desired by making the number of agents sufficiently large (see for example Arrow and Hahn (1971)). In this construction the sectoral income streams become the $\boldsymbol{A}$ basic goods that are traded on markets: the fact that the number of sectors is fixed, while the number of agents $I$ becomes very large, serves the dual role of justifying the competitive pricing of the sectoral income streams and of ensuring that the per-capita error in the matching of supply and demand for these streams become small.
} 
III. Constrained Efficiency

\section{Constrained Efficiency}

A well-known result of Diamond (1967)asserts that in a model similar to the one considered in this paper, but in which there are no incentive effects, the stock market leads to efficient investment and risk sharing, the efficiency being relative to the existing structure of securities - in short, he proved that a stock market equilibrium is constrained efficient. When the firms' profit functions $f^{i}\left(z^{i}, \mathrm{e}^{\prime}\right)$ are independent of $\mathrm{e}^{\prime}$, so that the effort variables are omitted, the model we are studying reduces to Diamond's model of the stock market. Does the constrained efficiency result carry over to the more general version of the model in which entrepreneurs' incentives are explicitly taken into account? Since the stock market cannot achieve risk sharing without distorting incentives, the question arises whether this trade-off is achieved in an optimal way at an equilibrium. In their attempt to diversify their risks, do outside shareholders acquire excessively large holdings in the firms, leading to undue distortion of the entrepreneurs' incentives to invest effort in their firms? Or, on the contrary, are the entrepreneurs unduly reluctant to sacrifice ownership shares in their profit streams, thus robbing other agents of potential opportunities for risk sharing? To answer these questions we need to generalize the concept of constrained efficiency introduced by Diamond to the context of this model. This means introducing a concept of constrained feasible allocations, which respects the limited trading opportunities achievable by a system of bond and equity markets, and in addition respects the incentive constraints imposed by the nonobservability of effort. Applying the Pareto ranking criterion to this constrained feasible set leads to the concept of a constrained Pareto optimum.

Definition 3: An allocation $(\boldsymbol{x}, \mathrm{e})=\left(\mathrm{x}^{\mathrm{i}}, e^{i}\right)_{i=1}^{I}$ is constrained feasible if there exist inputs and portfolios $(\boldsymbol{r}, b, \theta)=\left(z^{i}, b^{i}, \theta^{i}\right)_{i=1}^{I} \in \mathbb{R}_{+}^{I} \times \mathbb{R}^{I} \times R_{+}^{I I}$ such that

$$
\begin{aligned}
\sum_{i=1}^{I} x_{0}^{i} & =\sum_{i=1}^{I} w_{0}^{i}-\sum_{i=1}^{I} z^{i} \\
\sum_{i=1}^{I} b^{i} & =0 \\
\sum_{i=1}^{I} \theta_{k}^{i} & =1, k=1, \ldots, I
\end{aligned}
$$

and for each agent $i=1, \ldots, I$

$$
x_{1}^{i}=-b^{i} 1+\sum_{k=1}^{I} \theta_{k}^{i} f^{k}\left(z^{k}, e^{k}\right) \eta^{\alpha(k)}
$$


III. Constrained Efficiency

$$
e^{i}=\tilde{e}^{i}\left(m^{i}, z^{i}, \theta_{i}^{i}\right), \quad m^{i}=-b^{i} 1+\sum_{k \neq i} \theta_{k}^{i} f^{k}\left(z^{k}, e^{k}\right) \eta^{\alpha(k)}
$$

An allocation $(\boldsymbol{x}, \mathrm{e})$ is constrained Pareto optimal (CPO), if it is constrained feasible, and if there does not exist any alternative constrained feasible allocation $(\widehat{\boldsymbol{x}}, \widehat{\boldsymbol{e}})$ such that $U^{i}\left(\widehat{\boldsymbol{x}}^{i}, \tilde{e}^{i}\right) \geq$ $U^{i}\left(\boldsymbol{x}^{i}, \mathrm{e}^{\mathrm{i}}\right), \mathrm{i}=1, \ldots, \mathbf{I}$ with strict equality for at least one $\mathrm{i}$.

\section{A. Constrained Efficiency of Stock Market}

We can think of a CPO allocation as being achieved by a "planner" who chooses the investment-portfolio variables $\left(z^{i}, b^{i}, \boldsymbol{\theta}^{i}\right)$ in place of the agents, without having to respect their date 0 budget constraints, since he chooses their date 0 consumption $\left(x_{0}^{i}\right)$ directly. The planner has to respect the fact that entrepreneurs will personally choose their effort levels based on the incentives created by his choice of investment-portfolio variables $\left(\mathrm{z}^{\mathrm{i}}, b^{\boldsymbol{i}}, \boldsymbol{\theta}^{\boldsymbol{i}}\right)$.

Although it might seem unlikely that a competitive price mechanism could lead to a constrained Pareto optimal allocation in the presence of incentive constraints, it turns out that Diamond's result on constrained efficiency of the stock market does extend to the present model. The key to making this possible is the concept of rational, competitive price perceptions, which as we will explain in more detail after the next proposition, plays the role of an "incentive contract" designed by the outside shareholders for each entrepreneur.

Proposition 3: If $\mathcal{E}\left(u, w_{0}, F\right)$ is an economy satisfying the assumptions of Section $\Pi$, then every RCPP equilibrium is constrained Pareto optimal.

Proof: If the equilibrium $\left((\mathrm{x}, \overline{\boldsymbol{e}}, \overline{\boldsymbol{z}}, \boldsymbol{b}, \overline{\boldsymbol{\theta}}),\left(\bar{q}_{0}, \mathrm{Q}\right)\right.$; Q) is not CPO, then there is a constrained feasible allocation $(\mathrm{x}, \boldsymbol{e}, \boldsymbol{z}, \boldsymbol{b}, \theta)$ satisfying (11)-(15) such that $u^{i}\left(\boldsymbol{x}^{i}, \mathrm{e}^{\mathrm{i}}\right) \geq u^{i}\left(\overline{\boldsymbol{x}}^{i}, \bar{e}^{i}\right), \mathrm{i}=1, \ldots, \mathrm{I}$ with strict inequality for at least one $i$. By Proposition 2, Assumption MCMP implies that in an equilibrium all entrepreneurs invest a positive amount of capital and effort in the sector in which they are productive: as a result all income streams

$$
\left\{\eta^{\alpha} \mid a=\alpha(i) \text { and } F^{r} \neq 0 \text { for some i }\right\}
$$

can be traded in an equilibrium. Thus the date 1 consumption stream

$$
x_{1}^{i}=-b^{i} 1+\sum_{k \neq i} \theta_{k}^{i} f^{k}\left(z^{k}, e^{k}\right) \eta^{\alpha(k)}+\theta_{i}^{i} f^{i}\left(z^{i}, e^{i}\right) \eta^{\alpha(i)}
$$




\section{Constrained Efficiency}

would have been available to agent $i$, (when he in fact chose the equilibrium consumption $\overline{\boldsymbol{x}}_{1}^{i}$ ), had he chosen the investment, debt and ownership in his own firm $\left(z^{\prime}, b^{\prime}, \theta_{i}^{i}\right)$, and the portfolio of shares in other fims $\left(\tilde{\theta}_{k}^{i}\right)_{k \neq i}$ given by

$$
\widetilde{\theta}_{k}^{i} f^{k}\left(\bar{z}^{k}, \bar{e}^{k}\right)=\theta_{k}^{i} f^{k}\left(z^{k}, e^{k}\right)
$$

Given the outside income $\boldsymbol{m}^{i}$ derived from debt and other firms' securities, by constrained optimality, his choice of effort $e^{i}=\widetilde{e}^{i}\left(\boldsymbol{m}^{i}, z^{i}, \theta_{i}^{i}\right)$ would then have been optimal. Since $\left(x^{i}, e^{i}\right)$ is preferred or indifferent for all agents and. strictly preferred by at least one agent, the date 0 consumption must be at least as expensive.,and strictly more for some agent: thus

$$
x_{0}^{i} \geq w_{0}^{i}+\bar{q}_{0} b^{i}-\sum_{k \neq i} \bar{Q}_{k} \tilde{\theta}_{k}^{i}+\widetilde{Q}_{i}\left(z^{i}, b^{i},\left(\tilde{\theta}_{k}^{i}\right)_{k \neq i}, \theta_{i}^{i}\right)\left(1-\theta_{i}^{i}\right)-z^{i}, i=1, \ldots, I
$$

with strict inequality for some i. Note that by (9), and (ii) in Definition 1

$$
\begin{gathered}
\bar{Q}_{k} \tilde{\theta}_{k}^{i}=\bar{q}_{\alpha(k)} f^{k}\left(\bar{z}^{k}, \bar{e}^{k}\right) \tilde{\theta}_{k}^{i}=\bar{q}_{\alpha(k)} f^{k}\left(z^{k}, e^{k}\right) \theta_{k}^{i} \\
\widetilde{Q}_{i}\left(z^{i}, b^{i},\left(\tilde{\theta}_{k}^{i}\right)_{k \neq i}, \theta_{i}^{i}\right)=\bar{q}_{\alpha(i)} f^{i}\left(z^{i}, e^{i}\right)
\end{gathered}
$$

Summing (16) over i, using (17) and (18) gives

$$
\sum_{i=1}^{I} x_{0}^{i}>\sum_{i=1}^{I} w_{0}^{i}+\bar{q}_{0} \sum_{i=1}^{I} b^{i}-\sum_{i=1}^{I} \bar{q}_{\alpha(i)} f^{i}\left(z^{i}, e^{i}\right)\left(\sum_{k=1}^{I} \theta_{i}^{k}-1\right)-\sum_{i=1}^{I} z^{i}
$$

By feasibility $\sum_{i=l}^{I} \mathrm{~b}^{\mathrm{i}}=0$ and $\sum_{\mathrm{k}=1}^{I} \theta_{i}^{k}=1, i=1, \ldots, I$. But then (19) implies $\sum_{i=1}^{I} x_{0}^{i}>$ $\sum_{i=1}^{I} w_{0}^{i}-\sum_{i=1}^{I} z^{i}$, contradicting the constrained feasibility of $(\boldsymbol{x}, \mathrm{e}, \boldsymbol{z}, \boldsymbol{b}, \boldsymbol{\theta})$.

The standard framework for studying the optimal trade-off between risk sharing and incentives is the setting of a principal-agent problem. It is thus of some interest to note that the planner's problem of finding a CPO can be expressed as a generalized principal-agent problem. A principal (the planner), who can be thought of as owning all the resources, looks for a way of rewarding agents in the economy through the choice of consumption, investment and portfolio variables, so as to maximize a weighted sum of the agents' utilities under constraints which limit the risk-sharing possibilities at date 1 (constraints (14)), the incentive constraints (15), and subject to a reservation level of utility for himself equal to zero. This latter constraint expresses the fact that the principal appropriates no resources from the economy for himself, and is equivalent to the resource availability constraints (11)-(13). In this terminology, Proposition 3 


\section{Constrained Efficiency}

asserts that decentralized trading on the stock market leads to the solution of a principal-agent problem.

As is often the case, the first-order condition approach is more instructive than the abstract proof given above to understand what is involved in solving the CPO (principal-agent) problem and how this is achieved by the equilibrium concept described in Definition 2.

\section{B. First-Order Conditions for $C P O$}

In view of the boundary assumptions on the utility functions and assumption MCMP, at a CPO all the variables $x^{i}$ are positive and, for entrepreneurs, the variables $\left(z^{i}, e^{i}\right)$ are also positive. The only non-negativity constraints which need to be taken into account in deriving the first-order conditions (FOC) are the no-short-sales constraints $\theta_{k} \geq 0$. The FOC are more convenient to derive if the variables $(\mathrm{x}, \boldsymbol{e} ; \boldsymbol{z}, \mathrm{b}, \boldsymbol{\theta})$ are replaced by the variables $\left(\mathrm{x}, \boldsymbol{e} ; \boldsymbol{z}, \boldsymbol{b},\left(\left(\mu_{k}^{i}\right)_{k \neq i}, \theta_{i}^{i}\right)_{i=1}^{I}\right)$ where the relation between the two sets of variables is given by

$$
\mu_{k}^{i}=\theta_{k}^{i} f^{k}\left(z^{k}, e^{k}\right), \quad i \neq k
$$

The new variables $\left(\mu_{k}^{2}\right)_{k \neq i}$ reflect the fact that the production of firm $\mathrm{k}$ affects agent $\mathrm{i}$ only in so far as it affects his outside income $\mathrm{m}^{\mathrm{i}}$. In these new variables an allocation $(\boldsymbol{x}, \boldsymbol{e})$ is constrained feasible if there exist $\left(\boldsymbol{z}, \boldsymbol{b},\left(\left(\mu_{k}^{i}\right)_{k \neq i}, \theta_{i}^{i}\right)_{i=1}^{I}\right) \in \mathbf{R}_{+}^{I} \times \mathbf{R}^{I} \times \mathbf{R}_{+}^{I I}$ such that

$$
\begin{aligned}
\sum_{i=1}^{I} x_{0}^{i} & =\sum_{i=1}^{I} w_{0}^{i}-\sum_{i=1}^{I} z^{i} \\
\sum_{i=1}^{I} b^{i} & =0 \\
\sum_{k \neq i} \mu_{i}^{k} & \leq\left(1-\theta_{i}^{i}\right) f^{i}\left(z^{i}, e^{i}\right), \quad i=1, \ldots, I
\end{aligned}
$$

and for each agent $\mathrm{i}=1, \ldots, I$

$$
\begin{aligned}
x_{1}^{i} & =-b^{i} 1+\sum_{k \neq i} \mu_{k}^{i} \eta^{\alpha(k)}+\theta_{i}^{i} f^{i}\left(z^{i}, e^{i}\right) \eta^{\alpha(i)} \\
e^{i} & =\tilde{e}^{i}\left(-b^{i} 1+\sum_{k \neq i} \mu_{k}^{i} \eta^{\alpha(k)}, z^{i}, \theta_{i}^{i}\right)
\end{aligned}
$$

A constrained Pareto optimal allocation is a solution of the problem

$$
\max \sum_{i=1}^{l} \nu^{i}\left(u_{0}^{i}\left(x_{0}^{i}\right)+u_{1}^{i}\left(x_{1}^{i}\right)-c^{i}\left(e^{i}\right)\right)
$$




\section{Constrained Efficiency}

subject to the constraints $(20)-(24)$, where $\nu_{i}$ is the relative weight attached to the utility of agent $i$. To express the cost of each constraint in units of date 0 consumption, we divide all the multipliers by the multiplier $\lambda_{0}$ induced by the date 0 constraint (20). This gives a set of normalized multipliers $\left(1, q_{0},\left(q^{i}, \pi^{i}, \epsilon^{i}\right)_{i=1}^{I}\right)$ associated respectively with each of the constraints (20)-(24), where $\pi^{i}=\left(\pi_{1}^{i}, \ldots, \pi_{S}^{i}\right)$. The first-order conditions with respect to the variables $\left(\boldsymbol{x}^{i}, \mathrm{e}^{\prime}, z^{i}, \boldsymbol{b}, \mu_{k}^{i}, \theta_{i}^{i}\right)$ of an entrepreneur i are

$$
\begin{aligned}
\frac{\partial u_{1}^{i} / \partial x_{s}^{i}}{u_{0}^{i \prime}} & =\pi_{s}^{i}, s=1, \ldots, S \\
\frac{c^{i \prime}}{u_{0}^{i \prime}} & =\left(\left(1-\theta_{i}^{i}\right) q^{i}+\theta_{i}^{i} \pi^{i} \cdot \eta^{\alpha(i)}\right) \frac{\partial f^{i}}{\partial e^{i}}-\epsilon^{i} \\
1 & =\left(\left(1-\theta_{i}^{i}\right) q^{i}+\theta_{i}^{i} \pi^{i} \cdot \eta^{\alpha(i)}\right) \frac{\partial f^{i}}{\partial z^{i}}+\epsilon^{i} \frac{\partial \widetilde{e}^{i}}{\partial z^{i}} \\
q_{0} & =\pi^{i} \cdot 1+\epsilon^{i} \nabla_{m^{i}} \widetilde{e}^{i} \cdot 1 \\
q^{k} & \geq \pi^{i} \cdot \eta^{\alpha(k)}+\epsilon^{i} \nabla_{m^{i}} \widetilde{e}^{i} \cdot \eta^{\alpha(k)}, \quad k \neq i \\
q^{i} & =\pi^{i} \cdot \eta^{\alpha(i)}+\epsilon^{i} \frac{1}{f^{i}} \frac{\partial \widetilde{e}^{i}}{\partial \theta_{i}^{i}}
\end{aligned}
$$

where $\nabla_{m^{i}} \tilde{e}^{i}$ is the vector of partial derivatives (the gradient) of the effort function $\widetilde{e}^{i}\left(\boldsymbol{m}^{i}, \mathrm{z}^{\prime}, \theta_{i}^{\boldsymbol{i}}\right)$ with respect to $m^{i}=\left(m_{1}^{i}, \ldots, m_{S}^{i}\right)$ and where (29) holds with equality if $\mu_{k}^{i}>0$. To these equations should be added the FOC for the choice of optimal effort by entrepreneur $\mathbf{i}$

$$
c^{i \prime}\left(e^{i}\right)=\theta_{i}^{i} \nabla u_{1}^{i}\left(m^{i}+\theta_{i}^{i} f^{i}\left(z^{i}, e^{i}\right) \eta^{\alpha(i)}\right) \cdot \eta^{\alpha(i)} \frac{\partial f^{i}}{\partial e^{i}}\left(z^{i}, e^{i}\right)
$$

This is just the marginal way of expressing the incentive constraint $\mathbf{e}^{\prime}=\widetilde{e}^{i}(\cdot)$ in (24). Dividing this equation by $u_{0}^{i \prime}$ to make it comparable with (25) - (30), gives

$$
\frac{c^{i \prime}}{u_{0}^{i \prime}}=\theta_{i}^{i} \pi^{i} \cdot \eta^{\alpha(i)} \frac{\partial f^{i}}{\partial e^{i}}
$$

The first-order conditions with respect to the variables $\left(\mathrm{x}^{\prime}, \mu_{k}^{i}\right)$ of an investor are (25) and

$$
\begin{gathered}
q_{0}=\pi^{i} \cdot 1 \\
q^{k} \geq \pi^{i} \cdot \eta^{\alpha(k)} \quad\left(=\text { if } \mu_{k}^{i}>0\right), \quad k \neq i
\end{gathered}
$$




\section{Constrained Efficiency}

\section{Economic Interpretation of FOC}

Equation (25) defines the present-value vector $\mathbf{a}^{i}=\left(\pi_{1}^{i}, \ldots, \pi_{S}^{i}\right)$ of agent $\mathrm{i}$ : for any date 1 income stream $\mathrm{v}=\left(v_{1}, \ldots, v_{S}\right), \pi^{i} \cdot \mathrm{v}$ is the present value to agent $\mathrm{i}$ of the income stream $\boldsymbol{v}$. The variables $\left(q_{0}, q^{1}, \ldots, q^{I}\right)$ are the social values (shadow prices) of the income streams (securities) $\left(1, \boldsymbol{\eta}^{\alpha(1)}, \ldots, \boldsymbol{\eta}^{\alpha(I)}\right) . \epsilon^{i}$, which is the social cost of the incentive constraint (24), is the social value of (one unit of) effort by agent $\mathbf{i}$. The equations (28) - (30) and (28') - (29'), i.e. the first-order conditions with respect to $\left(b^{i}, \mu_{k}^{i}, \theta_{i}^{i}\right)$, express the limited sense in which there must be equalization of marginal rates of substitution to achieve a CPO allocation, full equalization being prevented by the fact that income can only be distributed indirectly using securities, and that the incentive constraints of the agents must be satisfied.

For each security, 1 or $\eta^{\alpha(k)}$, the private benefit to agent $\mathrm{i}$ of an additional (marginal) unit of the security is $\boldsymbol{\pi}^{i} \cdot \mathbf{1}$ or $\boldsymbol{\pi}^{i} \cdot \eta^{\alpha(k)}$. If agent $\mathrm{i}$ is an investor, then the private benefit coincides with the social benefit and (28') and (29') express the equalization of social (marginal) benefit and social (marginal) cost - these are the standard FOC for an optimal portfolio problem. Suppose now that agent $\mathrm{i}$ is an entrepreneur and $\mathrm{i} \neq \mathrm{k}$. An additional unit of security $\mathbf{1}$ or $\eta^{\alpha(k)}$ creates more than just a direct marginal benefit: since the agent is an entrepreneur, an increase in his outside income has an indirect effect - for it changes his effort by $\Delta e^{i}=\nabla_{m^{i}} \tilde{e}^{i} .1$ or $\nabla_{m}, \tilde{e}^{i} \cdot \eta^{\alpha(k)}$ and since this effort has a social value $\epsilon^{i}$, the social value of this indirect effect is $\epsilon^{i} \Delta e^{i}$. If $\mathrm{i}=\mathrm{k}$, in order for agent $\mathrm{i}$ to receive an additional unit of the security of his own firm, his holding $\theta_{i}^{i} f^{i}\left(z^{i}, \mathrm{e}^{\prime}\right)$ must increase by one unit: this is equivalent to increasing $\theta_{i}^{i}$ by $\frac{1}{f^{i}}$. This increase in the shareholding of his own firm increases ${ }^{1 '}$ his effort by $\left(1 / f^{\prime}\right)\left(\partial \widetilde{e}^{i} / \partial \theta_{i}^{i}\right)$, the social value of which is $\epsilon^{i}\left(1 / f^{i}\right)\left(\partial \tilde{e}^{i} / \partial \theta_{i}^{i}\right)$. Thus (28)-(30) express equalization at the margin of the social cost and the social benefit of an additional unit of $1, \eta^{\alpha(k)}$ or $\eta^{\alpha(i)}$, where the social benefit is equal to the private benefit to entrepreneur i minus the indirect social cost of his changed effort.

The social value $\epsilon^{i}$ of an additional unit of effort by entrepreneur $i$ is defined by equation (26) which can be written as

$$
\epsilon^{i}=\left(\theta_{i}^{i} \pi^{i} \cdot \eta^{\alpha(i)} \frac{\partial f^{i}}{\partial e^{i}}+\left(1-\theta_{i}^{i}\right) q^{i} \frac{\partial f^{i}}{\partial e^{i}}\right)-\frac{c^{i \prime}}{u_{0}^{i \prime}}
$$

$\epsilon^{\imath}$ is the difference between the social marginal benefit $\theta_{i}^{i} \mathbf{a}^{\prime} \cdot \eta^{\alpha(i)} \frac{\partial f^{\prime}}{\partial e^{i}}+\left(1-\theta_{i}^{i}\right) q^{i} \frac{\partial f^{\prime}}{\partial e^{i}}$, namely the benefit to entrepreneur $i$ plus the benefit to "outside investors" who receive the share $\left(1-\theta_{i}^{n}\right)$

\footnotetext{
${ }^{11}$ In the text we take the most intuitive case where $\partial \widetilde{e}^{\widehat{y}} / \partial \theta_{i}^{i}>0$ i.e. increased ownership leads to increased effort. It can happen, when $b^{\prime}$ is sufficiently large, that income effects make this term negative (see Section IV).
} 


\section{Constrained Efficiency}

of his output, and the social marginal cost, which here coincides with the private $\operatorname{cost} c^{i \prime} / u_{0}^{i \prime}$, since entrepreneur $i$ is the only one to bear the cost of his effort. Since effort is chosen optimally by entrepreneur $i$, by the "envelope theorem", or more precisely by the FOC (31), the welfare effect on the entrepreneur of a marginal change in his effort is zero. Substituting (31) into (26') gives

$$
\epsilon^{i}=\left(1-\theta_{i}^{i}\right) q^{i} \frac{\partial f^{i}}{\partial e^{i}}
$$

The social value of an additional unit of effort by entrepreneur $i$ is the value to agents other than himself of the additional output that this effort would create $e^{12}$ thus $\varepsilon^{i}>0(=0)$ if and only if $\boldsymbol{\theta}_{\boldsymbol{i}}^{\boldsymbol{i}}<1(=1)$. When $\boldsymbol{\theta}_{\boldsymbol{i}}^{\boldsymbol{i}}<\mathbf{1}$ the effort of entrepreneur $\boldsymbol{i}$ affects all those agents $\mathbf{j}$ who obtain a share of his profit stream: there is thus an external effect, The incentive constraint implies that this external effect is not taken into account when agent $i$ makes his effort decision and this creates a cost $\epsilon^{i}$, which is the cost of separating ownership and control. This cost is however explicitly taken into account by the planner when he chooses $\left(z^{i}, b^{\mathrm{i}}, \theta^{i}\right)$.

The logic underlying the FOC (27') for the socially optimal investment in firm i should now be clear: the social cost of one unit of:investment at date 0 must equal the direct social benefit (the first term on RHS of (27)) plus the indirect social benefit $\left(\epsilon^{i} \partial \vec{e}^{i} / \partial z^{i}\right)$ from the increased effort by agent $i$ induced by this increment to the capital input of his firm.

It is also easy to check that the multipliers $\left(q^{1}, \ldots, q^{I}\right)$ lead to well-defined shadow prices $\left(q_{1}, \ldots, q_{A}\right)$ for the sectoral income streams $\left(\eta^{1}, \ldots, \eta^{A}\right)$. For if entrepreneurs $\mathrm{k}$ and $k^{\prime}$ are in the same sector i.e. if $\alpha(k)=\alpha\left(k^{\prime}\right)$, then $q^{k}=q^{k \prime}{ }^{13}$ Thus the shadow price of $\eta^{\alpha}$ is defined by $q_{\alpha}=q^{k}$ for all ksuch that $\alpha(k)=\alpha$.

\section{How the FOC for $C P O$ are Achieved at Equilibrium}

Since a stock market equilibrium is constrained Pareto optimal, entrepreneurs must - just like the planner in a CPO problem -- be induced to take into account the external effect of their effort on the welfare of others, namely the terms in $\epsilon^{i}$ in equations (26)-(30). In the standard model of competitive equilibrium, where prices are assumed to be independent of the quantities chosen, the price system cannot cope efficiently with externalities. However,

\footnotetext{
${ }^{12}$ Note that their benefit is evaluated using $q^{i}$, and not $\pi^{j} \eta^{\alpha(i)}$ for $j \neq i$, and thus incorporates the incentive cost of giving them a marginal increment in the income stream $\eta^{\alpha(i)}$.

${ }^{13}$ If both $\theta_{k}^{k}$ and $\theta_{k^{\prime}}^{k^{\prime}}$ are less than 1 , this follows from the FOC (29) or (29') for the agents who hold positive shares in at least one of these firms. If $\theta_{k}^{k}=\theta_{k^{\prime}}^{k^{\prime}}=1$, this follows from (29)-(30) for the agents $k$ and $k^{\prime}$ (with $\epsilon^{k}=\epsilon^{k^{\prime}}=0$ ). If $\theta_{k}^{k}<1$ and $\theta_{k^{\prime}}^{k^{\prime}}=1$, it follows fom (29)-(30) for entrepreneur $k^{\prime}$, and from (29) for agents with a positive share in firm $k$.
} 


\section{Constrained Efficiency}

in an RCPP equilibrium, there is a "non-competitive" part, namely the rational-anticipations component of the perception function $\tilde{Q}$ : while entrepreneurs take the prices $\left(q_{\alpha}\right)_{\alpha=1}^{A}$ of the factors $\left(\boldsymbol{\eta}^{\alpha}\right)_{\alpha=1}^{\boldsymbol{A}}$ as given, they recognize that the price that the market winl pay for their shares depends on investors' expectations of the effort that they will make. Since investors can deduce from the entrepreneurs' financial decisions what their effort will be, financial decisions end up playing the role of signals: in the process of choosing their "signals", entrepreneurs are led to internalize the externality.

The way in which the price perceptions force entrepreneurs to internalize the externality, can be clearly understood by matching the FOC at an equilibrium with the FOC for a CPO allocation. Consider the maximum :problem of an entrepreneur in a stock market equilibrium ((i) in Definition 1). Let $\bar{\lambda}^{i}=\left(\lambda_{b}^{i}, \lambda_{1}^{i}, \ldots, \bar{\lambda}_{S}^{i}\right) \in \mathbb{R}_{+}^{S+1}$ denote the vector of multipliers induced by the $S+1$ budget constraints: the normalized vector

$$
\bar{\pi}^{i}=\frac{1}{\bar{\lambda}_{0}^{i}}\left(\bar{\lambda}_{1}^{i}, \ldots, \bar{\lambda}_{S}^{i}\right)=\left(\bar{\pi}_{1}^{i}, \ldots, \bar{\pi}_{S}^{i}\right)
$$

is the present-value vector of agent $i$ at the equilibrium. The first-order conditions are

$$
\begin{aligned}
\frac{\partial u_{1}^{i} / \partial x_{s}^{i}}{u_{0}^{i \prime}} & =\bar{\pi}_{s}^{i}, \quad s=1, \ldots, S \\
\frac{c^{i \prime}}{u_{0}^{i \prime}} & =\bar{\theta}_{i}^{i} \bar{\pi}^{i} \cdot \eta^{\alpha(i)} \frac{\partial f^{i}}{\partial e^{i}} \\
1 & =\bar{\theta}_{i}^{i} \bar{\pi}^{i} \cdot \eta^{\alpha(i)} \frac{\partial f^{i}}{\partial z^{i}}+\left(1-\bar{\theta}_{i}^{i}\right) \frac{\partial \tilde{Q}_{i}}{\partial z^{i}} \\
q_{0} & =\bar{\pi}^{i} \cdot 1+\left(1-\bar{\theta}_{i}^{i}\right) \frac{\partial \widetilde{Q}_{i}}{\partial b^{i}} \\
\bar{Q}_{k} & \geq \bar{\pi}^{i} \cdot \eta^{\alpha(k)} f^{k}+\left(1-\bar{\theta}_{i}^{i}\right) \frac{\partial \tilde{Q}_{i}}{\partial \theta_{k}^{i}},\left(=\text { if } \bar{\theta}_{k}^{i}>0\right), k \neq i \\
\bar{Q}_{i} & =\bar{\pi}^{i} \cdot \eta^{\alpha(i)} f^{i}+\left(1-\bar{\theta}_{i}^{i}\right) \frac{\partial \tilde{Q}_{i}}{\partial \theta_{i}^{i}}
\end{aligned}
$$

By paying attention to the way potential shareholders react to his financial decisions $\left(z^{i}, b^{i}, \theta^{i}\right)$, through the partial derivatives $\left(\partial \tilde{Q}_{i} / \partial z^{i}\right.$, etc $\left.\ldots\right)$, entrepreneur $i$ is led to take their interests into account. With the rational, competitive price perceptions $\widetilde{Q}_{i}$ defined by $(9)$, these partial 
derivatives are given by

$$
\begin{aligned}
& \frac{\partial \widetilde{Q}_{i}}{\partial z^{i}}=q_{\alpha(i)} \frac{\partial f^{i}}{\partial z^{i}}+\bar{q}_{\alpha(i)} \frac{\partial f^{i}}{\partial e^{i}} \frac{\partial \widetilde{e}^{i}}{\partial z^{i}} \\
& \frac{\partial \widetilde{Q}_{i}}{\partial b^{i}}=\bar{q}_{\alpha(i)} \frac{\partial f^{i}}{\partial e^{i}} \nabla_{m^{i}} \tilde{e}^{i} \cdot 1 \\
& \frac{\partial \widetilde{Q}_{i}}{\partial \theta_{k}^{i}}=\bar{q}_{\alpha(i)} \frac{\partial f^{i}}{\partial e^{i}} \nabla_{m^{i}} \tilde{e}^{i} \cdot \eta^{\alpha(k)} f_{1}^{k} \quad k \neq i \\
& \frac{\partial \tilde{Q}_{i}}{\partial \theta_{i}^{i}}-\bar{q}_{\alpha(i)} \frac{\partial f^{i}}{d e^{i}} \frac{\partial \tilde{e}^{i}}{\partial \theta_{i}^{i}}
\end{aligned}
$$

Substituting (39) - (42) into (33) - (38), and setting $q^{i}=\bar{q}_{\alpha(i)}, \epsilon^{i}=\left(1,-\bar{\theta}_{i}^{i}\right) \bar{q}_{\alpha(i)} \frac{\partial f^{i}}{\partial e^{i}}$ for $\mathbf{i}=1, \ldots$, I gives the FOC (25)-(31) for a constrained Pareto optimal allocation.

In letting himself be guided by the price perceptions' $\widetilde{Q}_{\boldsymbol{i}}\left(z^{i}, b^{\mathrm{i}}, \boldsymbol{\theta}^{\mathfrak{l}}\right)$, an entrepreneur understands, for example, that if he doubles the share $\left(1-\theta_{i}^{i}\right)$ of his firm that he sells, this will not double the income he receives: for shareholders know that when his ownership share falls, the effort that the entrepreneur will invest in his firm will fall, and this is reflected in the smaller price $\widetilde{Q}_{i}$ that shareholders will pay for the shares. He also knows that if he uses the proceeds of the sale for personal consumption or to buy shares in other firms, he will get less than if he uses the proceeds to finance capital expenditure for the firm.

There is an interesting connexion between Proposition $\mathbf{3}$ and the conditions for constrained (second best) optimality in an insurance market with moral hazard (Hellwig (1983), HenrietRochet (1991), Lisboa (1996)). In the insurance models, nonlinear prices are needed to obtain constrained optimality, and in such models the insurance companies are the natural intermediaries for implementing such "second-best optimal" nonlinear pricing. In the stock market, price perceptions induce nonlinear prices: thus rational behavior and anticipation on the part of agents can act as an alternative mechanism for achieving constrained efficiency to having intermediaries that charge explicit nonlinear prices. ${ }^{14}$

\section{Qualitative Properties of Stock Market Equilibria}

We have computed the equilibria of many families of economies by varying the parameters of the model and find that they behave in a regular way. In this section we report on some of

\footnotetext{
${ }^{14}$ In practice the underwriters who undertake to float an issue of shares on behalf of a firm help to make clear to the company how the market is going to evaluate their issue of shares. From the perspective of our model, in addition to matching supply and demand, their role is to help "entrepreneurs" to form rational, competitive price perceptions.
} 


\section{Qualitative Properties of Stock Market Equilibria}

these results, focusing on the differences between the properties of stock market equilibria with incentives and those of the familiar risk-sharing models of the CAPM type. The results which are summarized in Tables 1-4 show two types of equilibria for economies with the following characteristics:

- there are three (types of) agents, two entrepreneurs (agents 1 and 2) and one investor (agent 3)

- there are three states of nature of equal probability

- the agents have additively separable utility functions

$$
\begin{gathered}
U^{i}\left(x_{0}, x_{1}, x_{2}, x_{3}, e\right)=v^{i}\left(x_{0}\right)+\delta_{i} \sum_{s=1}^{3}(1 / 3) v^{i}\left(x_{s}\right)-c^{i}(e) \\
v^{i}(x)=\sqrt{x-a_{i}}, a_{1}=a_{2}=0, a_{3}=50, \delta_{i}=0.9, c^{i}(e)=\beta e^{\gamma}, \quad \beta=1.8, \gamma=2
\end{gathered}
$$

Thus the utility functions for date 1 consumption are expected discounted utility, with $v^{i}$ taken from the LRT (linear risk tolerance) family ${ }^{15}$. All agents have the same coefficient of marginal risk tolerance (equal to 2 ) and agent $\mathbf{3}$, with a negative intercept, is less risk tolerant than the others.

- the entrepreneurs' production possibilities are given by

$$
\boldsymbol{F}^{\prime}(z, e)=(z)^{1 / 2}(e)^{3 / 4} \eta^{i} \quad \text { with } \boldsymbol{\eta}^{1}=\left[\begin{array}{c}
22 \\
15 \\
8
\end{array}\right], \eta^{2}=\left[\begin{array}{c}
30 \\
10 \\
14
\end{array}\right]
$$

Thus activity 1 with mean $E\left(\eta^{1}\right)=15$ and standard deviation $\sigma\left(\eta^{1}\right)=5.7$ is less productive, but less risky, than activity 2 , for which $E\left(\eta^{2}\right)=18$ and $\sigma\left(\eta^{2}\right)=8.6$. The two activities are positively correlated with correlation coefficient $\operatorname{cor}\left(\mathrm{q}^{1}, \eta^{2}\right)=0.76$.

- the economy has a fixed date 0 wealth

$$
w_{0}^{1}+w_{0}^{2}+w_{0}^{3}=400
$$

We consider two distributions of initial wealth between entrepreneurs and investors given by

$$
\left(80^{\prime} 80,240\right) \text { and }(20,20,360)
$$

\footnotetext{
${ }^{15}$ For an expected utility function $E(v(x))$, the risk tolerance is defined by $T(x)=-v^{\prime}(x) / v^{\prime \prime}(x)$. The function $v$ is in the LRT family if $T(x)=\mathrm{A}+B x$. A is the intercept and $\mathrm{B}$ is the coefficient of marginal risk tolerance. Here $A_{1}=A_{2}=0, A_{3}=-100$ and $B_{i}=2$ for all agents.
} 
To show how the incentive effects change the predictions of the model with respect to risk sharing, security prices, and the use of debt versus equity, when compared with the standard CAPM-like model of finance, we computed two types of equilibria. First, the RCPP stock market equilibrium (Tables 1 and 3); second, the risk sharing equilibrium of the associated finance economy in which firms have the same physical investment and output $\left(z^{i}, y^{\prime}\right)$ as in the RCPP equilibrium, but where the production plans are taken as fixed and independent of the consumption-portfolio choices of the agents. The consumption-portfolio choices and security prices of this latter equilibrium are those that would be predicted by an outside observer knowing the agents' risk-impatience characteristics and the firms' production plans, but who is not aware of the feedback between the entrepreneurs' financial decisions and their choices of effort. Since we have chosen utility functions in the LRT family and since there are well-known properties for the equilibria of a finance economy with such preferences, we call this latter type of equilibrium an LRT equilibrium (Tables 2 and 4).

\section{A. Comparing RCPP and LRT Equilibria}

Consider first the case where there is a relatively even distribution of initial wealth between entrepreneurs and investors (Tables 1 and 2). For both equilibria the agents have essentially the same date 0 consumption and the same: mean consumption at date 1 . Even though the aggregate risk is the same for the two equilibria, what differs is the way the risk is distributed among the agents. In the RCPP-equilibrium, agent 2, who operates the riskier (and more productive) firm carries more than twice the risk of agent 1 and more than three times that of agent 3; in the LRT equilibrium while agent 2 still carries a slightly larger share than the others, much of his risk has been spread to agents 1 and $\mathbf{3}$.

A similar result hold for Tables $\mathbf{3}$ and 4, although now it becomes clear that the way risk is shared in both types of equilibria depends not only on the initial risks of the agents, but also on the way the initial wealth is distributed among them. In the RCPP-equilibrium agent 2 has roughly twice the risk of agents 1 and 3 , but in the LRT equilibrium the risk is shifted from agents 1 and 2 to the much wealthier agent $3 .^{16}$

The fact that entrepreneurs end up holding a larger share of the aggregate risk in a RCPPequilibrium than in an LRT-equilibrium conoes from the rather different'forces at work in the two types of equilibria. An LRT-equilibrium is a classical risk-sharing equilibrium, and by a

\footnotetext{
${ }^{16}$ Note that a similar result about the way risks are shared among the agents in the equilibria of Tables 1-4 holds if we use $\sigma\left(x_{1}^{i}\right) / E\left(x_{1}^{i}\right)$, namely risk per unit of' mean, as a measure of an agents exposure to risk.
} 
IV. Qualitative Properties of Stock Market Equilibria

\begin{tabular}{|c||c|c|c|c||c|c||c|c||c|c|c|}
\hline \multicolumn{10}{|c|}{ Table 1: RCP'P Stock Market Equilibrium } \\
\hline \hline & $x_{0}$ & $x_{1}$ & $x_{2}$ & $x_{3}$ & $\mathrm{E}\left(\boldsymbol{x}_{1}\right)$ & $\sigma\left(\boldsymbol{x}_{\mathbf{1}}\right)$ & $\mathrm{e}$ & $\boldsymbol{z}$ & $\mathrm{b}$ & $\boldsymbol{\theta}_{\mathbf{1}}(\boldsymbol{\%})$ & $\boldsymbol{\theta}_{\mathbf{2}}(\boldsymbol{\%})$ \\
\hline \hline agent 1 & 64 & 107 & $\mathbf{6 8}$ & 28 & 68 & 32 & 0.98 & 43 & 17 & 87 & 0 \\
\hline agent 2 & 83 & 201 & 29 & 64 & 98 & 74 & 1.24 & 85 & 57 & 0 & 80 \\
\hline agent 3 & 126 & 158 & 108 & 111 & 126 & 23 & 0 & 0 & -74 & 13 & 20 \\
\hline \hline $\begin{array}{c}\text { aggregate }^{a} \\
\text { returns }^{b}(\%)\end{array}$ & 273 & $\mathbf{4 6 6}$ & $\mathbf{2 0 5}$ & $\mathbf{2 0 3}$ & 292 & 124 & & & 7.8 & 4.7 & 7.3 \\
\hline
\end{tabular}

aggregate consumption at each date in each state which for date 1 is equal to aggregate output

b the last row of the " $b$ " column gives the interest rate $r$ (percent); the last row of the $\theta_{i}$ column give the risk premium $r_{i}-r$ (percent) for each firm $i=1,2$.

\begin{tabular}{|c||c|c|c|c||c|c||c|c|c|}
\hline \multicolumn{10}{|c|}{$w_{0}=(80,80,240)$} \\
\hline \hline & $x_{0}$ & $x_{1}$ & $x_{2}$ & $x_{3}$ & $\mathrm{E}\left(\boldsymbol{x}_{1}\right)$ & $\sigma\left(\boldsymbol{x}_{1}\right)$ & $b$ & $\boldsymbol{\theta}_{\mathbf{1}}(\%)$ & $\boldsymbol{\theta}_{2}(\%)$ \\
\hline \hline agent 1 & 64 & 119 & 44 & 44 & 69 & 35 & 14 & 29 & 29 \\
\hline agent 2 & 84 & 157 & 59 & 59 & 92 & 47 & 19 & 38 & 38 \\
\hline agent 3 & 125 & 190 & 102 & 102 & 131 & 42 & -33 & 33 & 33 \\
\hline $\begin{array}{c}\text { aggregate }^{\boldsymbol{a}} \\
\text { returns }^{b}(\%)\end{array}$ & 273 & 466 & 205 & 203 & 292 & 124 & 6.4 & 8.1 & 11.8 \\
\hline $\boldsymbol{a}, b$
\end{tabular}

a,b same definition as in Table 1

\begin{tabular}{|c||c|c|c|c||c|c||c|c||c|c|c|}
\hline \multicolumn{10}{|c|}{ Table 3: RCPP Stock Market Equilibrium } \\
$w_{0}=(20,20,360)$ \\
\hline \hline & $x_{0}$ & $x_{1}$ & $x_{2}$ & $x_{3}$ & $\mathrm{E}\left(\boldsymbol{x}_{1}\right)$ & $\sigma\left(\boldsymbol{x}_{1}\right)$ & $\boldsymbol{e}$ & $\boldsymbol{z}$ & $\boldsymbol{b}$ & $\boldsymbol{\theta}_{\mathbf{1}}(\%)$ & $\boldsymbol{\theta}_{\mathbf{2}}(\%)$ \\
\hline \hline agent 1 & 32 & 82 & 44 & 6 & 44 & 31 & 1.16 & 46 & 37 & 71 & 0 \\
\hline agent 2 & 51 & 169 & 9 & 41 & 73 & 69 & 1.41 & 86 & 72 & 0 & 67 \\
\hline agent 3 & 186 & 274 & 180 & 181. & 212 & 44 & 0 & 0 & -109 & 29 & 33 \\
\hline \hline $\begin{array}{c}\text { aggregate }^{\boldsymbol{a}} \\
\text { returns }^{\boldsymbol{b}}(\%)\end{array}$ & 269 & 525 & 233 & 228 & 329 & 139 & & & 18.5 & 4.9 & 7.2 \\
\hline $\boldsymbol{a . 0}$ Same definition as in Table 1 &
\end{tabular}

${ }^{a, b}$ Same definition as in Table 1

\begin{tabular}{|c|c|c|c|c|c|c|c|c|c|}
\hline \multicolumn{10}{|c|}{$\begin{array}{c}\text { Table 4: LRT Equilibrium } \\
\qquad w_{0}=(20,20,360)\end{array}$} \\
\hline & $x_{0}$ & $x_{1}$ & $x_{2}$ & $x_{3}$ & $E\left(x_{1}\right)$ & $\sigma\left(x_{1}\right)$ & $b$ & $\theta_{1}(\%)$ & $\theta_{2}(\%)$ \\
\hline agent 1 & 33 & 71 & 28 & 27 & 42 & 21 & 7 & 15 & 15 \\
\hline agent 2 & & 112 & 43 & 42 & 66 & 33 & & & 24 \\
\hline agent 3 & 185 & 342 & 162 & 159 & 221 & 85 & -19 & & \\
\hline $\begin{array}{l}\text { aggregate }^{a} \\
\text { returns }{ }^{b}(\%)\end{array}$ & 269 & 525 & 233 & 228 & 329 & 139 & 15.8 & 8.7 & 12.5 \\
\hline
\end{tabular}


IV. Qualitative Properties of Stock Market Equilibria

well-known result in the finance literature "', in such an equilibrium agents have fully diversified portfolios, more precisely, $\theta_{1}^{i} / \theta_{2}^{i}=1, i=1,2,3$ : this result is clear in Tables 2 and 4 . By contrast, in the RCPP-equilibrium there are limits to how much of their production risks entrepreneurs can diversify away by selling shares of their own firms and buying those of others: the market knows that the effort exerted by an entrepreneur depends on the ownership share of his firm that he retains. Entrepreneurs retain a higher proportion of their firm in a RCPPequilibrium than in an LRT-equilibrium: as a result, entrepreneurs typically make more use of debt to finance their capital investment in a RCPP-equilibrium than in an LRT-equilibrium.

This qualitative difference in the financial choices of the entrepreneurs has consequences for the dual variables, namely the prices of the securities. Since what matters for securities are their rates of return, we follow standard practice and express these properties in terms of the rate of interest $(\mathrm{r})$ on the bond, and the risk premia $\left(r_{i}-r\right)$ on the securities, where

$$
1+r=\frac{1}{q_{0}}, \quad 1+r_{i}=\frac{E\left(y^{i}\right)}{Q_{i}}, \quad i=1,2
$$

and $y^{i}=\left(y_{1}^{i}, \ldots, y_{S}^{i}\right)$ is the date 1 profit stream of firm $i$. The risk premium on security $i$ is the excess return per unit of income invested in security $i$ over of the riskless return $(1+\mathrm{r})$ on the bond, - the excess return being the compensation required for carrying the risk associated with security $i$ (at equilibrium).

Since entrepreneurs typically borrow more and sell a smaller proportion of the share of their firms in a RCPP-equilibrium, the mte of interest is higher and the risk premia on securities are lower in a RCPP-equilibrium than in an LRT-equilibrium. Entrepreneurs by restricting the supply of their firms' shares that they offer for sale, drive up the prices of equity contracts, thus lowering their risk premia ${ }^{18}$. The entrepreneurs who need outside funds to finance their capital investment resort to increased borrowing thereby increasing the rate of interest.

\section{B. Comparing RCPP Equilibria}

Further insight into the forces at work in an RCPP-equilibrium can be obtained by comparing the outcomes when the distribution of initial wealth is shifted away from entrepreneurs towards investors (Tables 1 and 3). Even though for the equilibrium of Table $\mathbf{3}$ entrepreneurs

\footnotetext{
${ }^{17}$ For a summary of the properties of LRT economies, see for example Magill and Quinzii (1996, Section 17).

${ }^{18}$ This result seems to make the "equity premium puzzlen even more of a puzzle. However the observed high return on equity comes from capital gains rather than a high dividend yield, and capital gains are not present in our two-period model. A multiperiod model would be needed to determine whether the incentive-basedrestriction of the supply of equity could be a factor contributing to large capital gains
} 
have much less initial wealth at their disposal, a egate output is increased. This increased output comes from the increased effort of the entrepreneurs, for their capital investment is (essentially) unchanged. Their reduced initial wealth forces them to draw more extensively on the equity and bond markets for outside sources of funds. If the entrepreneurs were to rely principally on equity to finance their capital expenditure, then there would be a substantial drop in the prices of the firms' shares - for the market knows that a significant reduction in the ownership shares of the entrepreneurs will lead thegn to invest much less effort in their firms. The entrepreneurs are thus unlikely to find it optimal to finance their capital expenditures exclusively by the sale of equity.

But if selling equity has a negative effect on incentives (and thus on price), incurring debt has exactly the opposite effect. For a one unit increase in debt leads to a one unit decrease in consumption in each state at date 1 and thus to an increase in the marginal utility of consumption in each state, thereby increasing the payoff (marginal benefit) of effort: thus more debt leads to more effort. This explains why the market interprets an increase in debt as a "favorable signal". There is however also a limit to how much debt an entrepreneur will want to incur: for a large debt leads to the threat of bankruptcy, and since (in this model) the cost of bankruptcy is infinite, he will be forced to make an enormous effort to be sure of paying back the debt in the most unfavorable state. Ultimately it is the cost of effort which limits the extent to which an entrepreneur resorts to debt as an outside source of funds. Given that in Table 3 entrepreneurs have less initial wealth than in Table 1, the optimal way of financing their capital investment involves both selling more equity and incurring more debt: the equity shares fall from about $90 \%$ to $70 \%$ for entrepreneur 1, and from $80 \%$ to $70 \%$ for entrepreneur 2 , while debt increases by $100 \%$ and $25 \%$ respectively. However the effect of debt dominates that of equity in that both entrepreneurs end up making more effort in the latter equilibrium.

The increased effort, by leading to greater productivity of the economy (for the same capital investment, output increases by $7 \%$ in Table 1 and by $22 \%$ in Table 3) leads to a substantial increase in the rate of interest (from 7.8 to $18.5 \%$ ). Even though the entrepreneurs sell more of their shares, the equity premia are essentially unchanged, since the outside investor is much wealthier and thus more tolerant to risk (more willing to invest in the stock market).

\section{Qualitative Properties of Effort Function}

The way in which debt and ownership jointly induce effort is made precise by the effort function which is shown in Figure 1. If we fix the capital investment of entrepreneur $i$ at its 
IV. Qualitative Properties of Stock Market Equilibria

equilibrium value $z^{2}=\bar{z}^{2}$ in Table 1 , and if we note that he does not invest in the other firm $\bar{\theta}_{j}^{i}=0$, then his optimal effort can be expressed as a function of his ownership share $\theta_{i}^{i}$ and his debt $b^{i}$

$$
e^{i}=h^{i}\left(\theta_{i}^{i}, b^{i}\right)=\widetilde{e}^{i}\left(-b^{i} 1, \bar{z}^{i}, \theta_{i}^{i}\right) .
$$

Figure 1 shows entrepreneur 2's effort function $e^{2}=h^{2}\left(\theta_{2}^{2}, b^{2}\right)$ viewed as a function of $\theta_{2}^{2}$ for different fixed values of $b^{2}$. The graph of the effort function of entrepreneur 1 has the same general form.

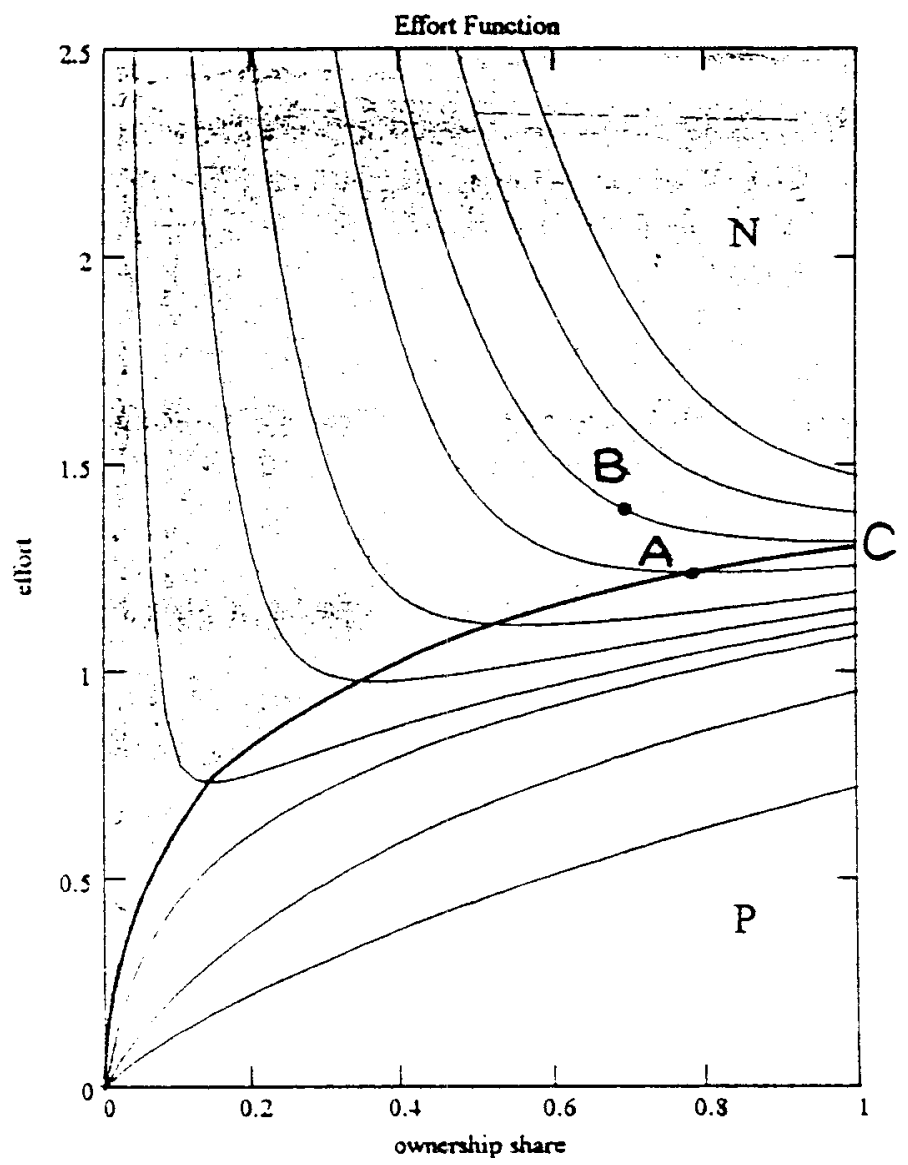

Figure 1: Graph of the effort function of entrepreneur 2 for different values of $b^{2}$ : starting with the top curve the values are $b^{2}=102,87,72,57,37,22,7,-8,-93,-393$.

For any fuxed ownership share $\theta_{i}^{i}$, increasing debt leads to an increase in effort ${ }^{19}$ : furthermore, the smaller the ownership share the greater the increase in effort induced by the increase in debt. When $b^{i}$ is either zero or negative (agent $i$ is a lender) then effort is an increasing func-

\footnotetext{
${ }^{19}$ It is easy to see, by differentiating the first-order condition defining the optimal effort function $\boldsymbol{e}^{i}$ that the property $\partial e^{i} / \partial b^{i}>0$ holds generally when $u_{1}^{i}$ is an expected utility
} 
tion of ownership and the more the agent lends the less effort he exerts; for any fuxed positive level of debt, there is always a critical level $\hat{\theta}_{i}^{i}(b)$ of ownership share such that for $\theta_{i}^{i}<\hat{\theta}_{i}^{i}$ effort is a decreasing function of $\theta_{i}^{i}$, and for $\theta_{i}^{i}>\hat{\theta}_{\boldsymbol{i}}^{i}$ it is an increasing function ${ }^{20}$. The increasing curve OC in Figure 1 defines these critical levels: thus $\partial \mathfrak{e}^{\mathfrak{z}} / \partial \theta_{i}^{\boldsymbol{\imath}}<0$ in the region $\mathrm{N}$ above OC and $\partial \vec{e}^{i} / \partial \theta_{i}^{i}>0$ in the region $\mathrm{P}$ below OC. The negative slope of the optimal effort function in the region $\mathrm{N}$ is akin to the income effect dominating the substitution effect in a standard microeconomic choice problem (interpreting effort as labor and $\theta_{i}^{i}$ as a wage, since the reward for effort is proportional to $\left.\theta_{i}^{i} f^{i}\left(\bar{z}^{i}, e^{\prime}\right)\right)$. The equation determining entrepreneur $i$ 's optimal effort is

$$
c^{i \prime}\left(e^{i}\right)=\theta_{i}^{i}\left(\sum_{s=1}^{S} \frac{\partial u_{1}^{i}\left(x_{1}^{i}\right)}{\partial x_{s}^{i}} \eta_{s}^{\alpha(i)}\right) \frac{\partial f^{i}}{\partial e^{i}} \quad \text { with } x_{1}^{i}=-b^{i} 1+\theta_{i}^{i} f^{i}\left(z^{i}, e^{i}\right) \eta^{\alpha(i)}
$$

Increasing the agents' ownership share $\theta_{i}^{\imath}$ has two effects: the direct (substitution) effect is to increase the marginal benefit from an addition unit of effort; the indirect (income) effect is to increase date 1 consumption $x_{1}^{i}$ and thus to decrease $\partial u^{i} / \partial x_{\boldsymbol{s}}^{i}$ (assuming additive separability), thus decreasing the marginal benefit of effort. When $x_{1}^{i}$ is small (small $\theta_{i}^{i}$ and large $b^{i}$ ), the marginal utility of consumption decreases fast and the negative indirect effect dominates, leading to the apparently paradoxical result that a reduced ownership share leads to increased effort. When $x_{1}^{i}$ is large (large $\theta_{i}^{i}$ and small or negative $b^{i}$ ) marginal utility changes very little with an additional unit of consumption, and the direct positive effect dominates: hence the intuitive result that increased ownership leads to increased effort.

In the region $\mathrm{N}$ the effort curves are asymptotic to the vertical axis, implying that effort must increase enormously when $\theta_{i}^{i} \longrightarrow 0$ : this is the no-bankruptcy effect. Since in this model the cost of bankruptcy is infinite, to be sure that the inequality $-b^{i}+\theta_{i}^{z} \mathrm{f}^{i}\left(z^{i}, e^{i}\right) \eta_{s}^{\alpha(i)} \geq 0$ is satisfied for all states, the smaller $\theta_{i}^{i}$, the greater the effort agent $i$ must expend to stay out of bankruptcy. While shareholders of firm $\mathrm{i}$ would be happy to see entrepreneur $i$ incurring a large debt and owning only a small share of his firm, the entrepreneur in choosing his financial variables $\left(z^{i}, b^{i}, \theta_{i}^{i}\right)$ will normally try to stay out of this region!

In the equilibrium of Table 1 , agent 2 is located at the point A: his ownership share $80 \%$ is essentially at the critical level for the amount borrowed $b^{2}=57$. For the equilibrium of Table 2, which can be represented by the same graph, since $\bar{\theta}_{1}^{2}=0$, and $\bar{z}_{2}$ is essentially unchanged, agent 2 is located at the point B: his low initial wealth forces him to borrow so much that he

\footnotetext{
${ }^{20}$ This behaviour of $\partial e^{i} / \partial \theta_{i}^{i}$ holds for LRT utility functions with a zero intercept and a coefficient of marginal risk tolerance greater than one $\left(v^{i}\left(x_{s}^{i}\right)=\left(x_{s}^{i}\right)^{\alpha}\right.$ with $\left.0<\alpha<1\right)$.
} 


\section{Appendix}

is on the decreasing segment of his effort curve.

Note that for $\bar{z}^{2}$ fixed and $\bar{\theta}_{1}^{2}=0$, the perception function $\widetilde{Q}_{2}$ is a function of $\left(b^{2}, \theta_{2}^{2}\right)$

$$
\widetilde{Q}_{2}\left(b^{2}, \theta_{2}^{2}\right)=-q_{2} f^{2}\left(\bar{z}^{2}, h^{2}\left(b^{2}, \theta_{2}^{2}\right)\right)
$$

so that up to a monotone transformation of the vertical axis, the same graph illustrates the perception function $\widetilde{Q}_{2}\left(b^{2}, \theta_{2}^{2}\right)$. Thus the general qualitative properties of the way effort responds to debt and ownership share translate into equivalent properties for the perception function $\widetilde{Q}_{2}\left(b^{2}, \theta_{2}^{2}\right)$. In particular selling equity can always be achieved without a drop in the price, provided debt is incurred at the same time.

\section{Conclusion}

With the exception of the well-known papers of Prescott and Townsend (1984a,b), general equilibrium theory and the economics of asymmetric information are two branches of economic theory which have remained surprisingly separate. With some exaggeration general equilibrium studies circumstances under which markets "work", while the theory of asymmetric information reveals the circumstances which make rnarkets "fail". Prescott and Townsend argue that in principle markets can resolve problems posed by asymmetry of information: however, to establish this result, they postulate the existence of an extensive array of markets for contracts (which rather like Arrow-Debreu contracts) are difficult to identify in the real world.

The approach of this paper is somewhat different: it seeks to formalize in a general equilbrium setting why the markets that we actually observe for debt and equity may perform rather well even in the presence of moral hazard. The main requirement, in addition to perfect competition, is that participants on these markets be rational, and that this rationality be common knowledge. This is formalized in the concept of rational, competitive price perceptions: it is the anticipatory aspect of perceptions which provides the disciplinary forces, or more precisely, the incentive schemes needed to motivate agents in the appropriate way.

\section{APPENDIX}

Proof of Proposition 2. (i) The first-order condition for the problem (E) is given by

$$
\frac{c^{i \prime}\left(e^{i}\right)}{\frac{\partial f^{i}}{\partial e^{i}}\left(z^{i}, e^{i}\right)} \geq \theta_{i}^{i} \sum_{s=1}^{S} \frac{\partial u_{1}^{i}}{\partial x_{s}^{i}}\left(\boldsymbol{m}^{i}+\theta_{i}^{i} f^{i}\left(z^{i}, e^{i}\right) \eta^{\alpha(i)}\right) \eta_{s}^{\alpha(i)}
$$




\section{References}

with equality if $\mathrm{e}^{\prime}>0$. Since $f^{i}\left(\mathrm{z}^{\mathrm{i}}, \cdot\right)$ is increasing, and $\frac{\partial \boldsymbol{u}_{i}^{i}(\cdot)}{\partial \boldsymbol{x}_{a}^{i}}$ is decreasing by concavity of $u_{1}^{i}$, the RHS of (Al) is a decreasing function of $e^{i}$, while LHS is increasing by $\operatorname{MCMP}(a)$. If at $e^{i}=0$, LHS exceeds RHS then $e^{i}=0$ is the solution; in the opposite case, since LHS goes to $\infty$ there is a unique e' $>0$ satisfying (A1) with equality, and the differentiability of this solution follows by applying the Implicit Function Theorem noting that MCMP(a) implies $c^{i \prime \prime} / c^{i \prime}>\frac{\partial^{2} f^{i}}{\partial^{2} e^{i}} / \frac{\partial f^{i}}{\partial e^{i}}$.

(ii) Let $\mathrm{AU}$ ' denote the difference in utility in (8) between investing $\left(\mathrm{z}^{\prime}, e^{i}\left(z^{i}\right)\right)$ in activity $\alpha(i)$ and investing $(0,0)$, where $e^{i}(\cdot)$ is the function defined in $\operatorname{MCMP}(\mathrm{b})$ and $z^{i} \leq \min \left\{x_{0}^{i} / 2,1\right\}$. Then

$$
\begin{aligned}
\Delta U^{i}=- & \int_{0}^{z^{i}} u_{0}^{i \prime}\left(x_{0}^{i}-t\right) d t-\int_{0}^{z^{i}} c^{i \prime}\left(e^{i}(t)\right) e^{i /(t)} d t \\
& \int_{0}^{z^{i}} \nabla u_{1}^{i}\left(x_{1}^{i}+f^{i}\left(t, e^{i}(t)\right) \eta^{\alpha:(i)}\right)\left[\frac{\partial f^{i}}{\partial z^{i}}\left(t, e^{i}(t)\right)+\frac{\partial f^{i}}{\partial e^{i}}\left(t, e^{i}(t)\right) e^{i \prime}(t)\right] \eta^{\alpha(i)} d t
\end{aligned}
$$

Set $\mathrm{k}=u_{0}^{i \prime}\left(x_{0}^{i} / 2\right), \mathrm{K}=\nabla u_{1}^{i}\left(x_{1}^{i}+f^{\imath}\left(1, e^{i}(1)\right) \eta^{\alpha(i)}\right) \cdot \eta^{\alpha(i)}$, then since $\frac{\partial f}{\partial r^{i}}>0, \frac{\partial f}{\partial e^{i}}>0$, $e^{i \prime}>0$ and $u_{0}^{i}$ and $u_{1}^{i}$ are concave

$$
\Delta U^{i} \geq \int_{0}^{z^{i}}\left(K \frac{\partial f^{i}}{\partial z^{i}}\left(t, e^{i}(t)\right)-k-c^{i \prime}\left(e^{i}(t)\right) e^{i \prime}(t)\right) d t
$$

By $\operatorname{MCMP}(b)$, for $z^{i}>0$ sufficiently small this expression is positive.

\section{References}

Arrow, Kenneth J., "Le Role des Valeurs Boursières pour la Répartition la Meillcure des Risques", in Econométrie, Colloques Internationaux du Centre National de la Recherche Scientifique, 1953, 40, pp. 41-47; English version: "The Role of Securities in the Optimal Allocation of Risk Bearing", Review of Economic Studies, April 1964, 31, pp. 91-96.

Arrow, Kenneth J. and Frank H. Hahn, General Competitive Analysis, San F'rancisco: Holden Day, 1971.

Berle, Adolph A. and Gardiner C. Means, The Modern Corporation and Private Property, New York: Harcourt, Brace and World, 1932.

Brander, James A. and Barbara J. Spencer., "Moral Hazard and Limited Liability: Implications for the Theory of the Firm", International Economic Review, November 1989, 30, pp. 833-849.

Cheung, Steven N.S., "Transaction Costs, Risk Aversion, and the Choice of Contractual Arrangements", The Journal of Law and Economics, April 1969, 12, pp. 23-42. 


\section{References}

Diamond, Peter A., "The Role of a Stock Market in a General Equilibrium Model with Technological Uncertainty", American Economic Review, 1967, 57, pp. 759-773.

Grossman, Sanford and Oliver Hart, "Corporate Financial Structure and Managerial Incentives", in: J. McCall, ed., The Economics of Information and Uncertainty. Chicago: University of Chicago Press, 1982, pp. 107-137.

Hammond, Peter, "Financial Distortions to the Incentives of Managers, Owners and Workers", Working Paper No. 50, University of Munich, Germany, November 1993.

Harris, Milton and Arthur Raviv, "Financial Contracting Theory", in Jean-Jacques Laffont ed., Advances in Economic Theory: Sixth World Congress, Volume 11, Cambridge: Cambridge University Press, 1992, pp. 64-150.

Hellwig, Martin, "On Moral Hazard and Non-Price Equilibria in Competitive Insurance Markets", Discussion Paper No. 109, University of Bonn, 1983.

Henriet, Dominique and Jean-Charles Rochet, Microéconomie de 1' Assurance, Paris: Economica, 1991.

Jensen, Michael C. and William H. Meckling, "Theory of the Firm: Managerial Behavior, Agency Costs, and Capital Structure", Journal of Financial Economics, 1976, 3, pp. 305360.

Knight, Frank H., Risk, Uncertainty and Profit, Boston: Houghton Mifflin, 1921.

Koopmans, Tjalling C., "Analysis of Production as an Efficient Combination of Activities", in Activity Analysis of Production and Allocation, T.C. Koopmans ed., Cowles Foundation Monograph, New York: Wiley, 1951.

Leland, Hayne and David Pyle, "Information Asymmetries, Financial Structure and Financial Intermediation, Journal of Finance, 19'77, 32, pp. 371-388.

Lisboa, Marcos B., "Moral Hazard and Nonlinear Pricing in a General Equilibrium Model, Working Paper, University of Pennsylvania, 1995.

Magill, Michael and Martine Quinzii, Theory of Incomplete Markets, Volume 1, Cambridge: MIT Press, 1996.

Magill, Michael J.P and Wayne Shafer, ",Incomplete Markets", in W. Hildenbrand and H. Sonnenschein, eds., Handbook of Mathematical Economics, Volume IV, Amsterdam: North Holland, 1991, pp. 1523-1614.

Marshall, Alfred, Principles of Economics, London: MacMillan, 1890.

Mill, John Stuart, Principles of Political Economy, London: J.W. Parker, 1848.

Prescott, Edward C. and Robert M. Townsend, "Pareto Optima and Competitive Equilibria with Adverse Selection and Moral Hazard", Econometrica, January 1984a, 52, pp. 21-46. 
Prescott, Edward C. and Robert M. Townsend, "General Competitive Analysis in an Economy with Private Information", International Ewnomic Review, February 1984b, 25, pp. 1-20.

Ross, Stephen A., "The Determination of Financial Structure: The Incentive-Signalling Approach", Bell Journal of Economics, Spring 1977, 8, pp. 23-40.

Sappington, David E., "Incentives in Principal-Agent Relationships", Journal of Economic Perspectives, Spring 1991, 5, pp. 45-66.

Stiglitz, Joseph E., "Incentives and Risk Sharing in Sharecropping", The Review of Ewnomic Studies, April 1974, 41, pp. 219-255.

Smith, Adam, An Inquiry into the Nature and Causes of the Wealth of Nations, London: W. Strahan and T. Cadell, 1776. 